\title{
Binder-jetting 3D printing and alloy development of new biodegradable $\mathrm{Fe}-\mathrm{Mn}-\mathrm{Ca} / \mathrm{Mg}$ alloys
}

Daeho Hong ${ }^{1}$, Da-Tren Chou ${ }^{1}$, Oleg I. Velikokhatnyi ${ }^{1}$, Abhijit Roy ${ }^{1}$, Boeun Lee ${ }^{1}$, Isaac Swink ${ }^{4}$, Ilona Issaev ${ }^{5}$, Howard A. Kuhn ${ }^{6}$, and Prashant N. Kumta ${ }^{1,2,3}$

${ }^{1}$ Department of Bioengineering

Swanson School of Engineering, University of Pittsburgh, Pittsburgh, PA 15261

${ }^{2}$ Department of Chemical and Petroleum Engineering

Swanson School of Engineering, University of Pittsburgh, Pittsburgh, PA 15261

${ }^{3}$ Department of Mechanical Engineering and Materials Science

Swanson School of Engineering, University of Pittsburgh, Pittsburgh, PA 15261

${ }^{4}$ Department of Engineering, Robert Morris University, Moon, PA 15108

${ }^{5}$ Department of Mechanical Engineering, Ort Braude College, Karmiel, Israel

${ }^{6}$ ExOne Company, Irwin, PA 15642 


\section{Abstract}

3D printing of various biomaterials including titanium and stainless steel has been studied for treating patients with cranio-maxillofacial bone defect. The potential long term complications with use of inert biometals have opened the opportunities for use of biodegradable metals in the clinical arena. The authors previously reported that binder-jet 3D printing technique enhanced the degradation rates of biodegradable Fe-Mn alloy by creating engineered micropores rendering the system attractive as biodegradable implantable devices.

In the present study, the authors employed CALPHAD modeling to systematically study and modify the Fe-Mn alloy composition to achieve enhanced degradation rates. Accordingly, $\mathrm{Ca}$ and $\mathrm{Mg}$ addition to $\mathrm{Fe}-35 \mathrm{wt} . \% \mathrm{Mn}$ solid solution predicted increase in degradation rates. In order to validate the CALPHAD results, $\mathrm{Fe}-(35-\mathrm{y})$ wt. $\% \mathrm{Mn}-\mathrm{y}$ wt. $\% \mathrm{X}(\mathrm{X}=\mathrm{Ca}, \mathrm{Mg}$, and y $=0,1,2)$ were synthesized by using high energy mechanical alloying (HEMA). Sintered pellets of $\mathrm{Fe}-\mathrm{Mn}-\mathrm{Ca}$ and $\mathrm{Fe}-\mathrm{Mn}-\mathrm{Mg}$ were then subjected to potentiodynamic polarization (PDP) and live/dead cell viability tests. Sintered pellets of Fe-Mn, Fe-Mn-Ca, and Fe-Mn-Mg also exhibited MC3T3 murine pre-osteoblast cells viability in the live/dead assay results. Fe-Mn and Fe-Mn$1 \mathrm{Ca}$ were thus accordingly selected for $3 \mathrm{D}$ printing and the results further confirmed enhanced degradation of $\mathrm{Ca}$ addition to $3 \mathrm{D}$ printed constructs validating the theoretical and alloy development studies. Live/dead and MTT cell viability results also confirmed good cytocompatibility of the 3D-printed Fe-Mn and Fe-Mn-1Ca constructs.

Keywords: 3D printing; bone defect; biodegradable metal; Fe-Mn alloy; and medical scaffold 


\section{Introduction}

Fixation screws, plates, and meshes have been widely used to reconstruct skull or facial fractures [1]. In most cases, these treatments result in a successful reunion of the remaining bone fragments. However, the treatments appear to fall short when there are civilians who have succumbed to severe automotive accidents, traumatic battlefield injuries, and cancerous conditions of the bone. Injuries such as these often involve a critical-sized bone defect (CSBD) that has a large region or segments of missing bone that the body's own homeostatic healing prowess alone is incapable of providing the necessary healing. As a result, the defect needs to be either filled with a synthetic bone void filler or a synthetic or naturally derived bone graft taken from the patient alone or from another donor $[2,3]$. Intraoperative adjustments have been widely used to prepare an autograft or allograft for reconstructive surgery [4]. Matching the geometry of the bone graft to that of the affected area is necessary in order to obtain satisfactory results. Hence, efforts have been made to improve the geometrical fit of the device by utilizing various CAD/CAM technologies and stereo-lithography techniques $[5,6]$.

Recently, 3-dimensional printing (3DP) has been explored as a fabrication method for patientspecific devices utilizing existing biomaterials such as PEEK [7], titanium [8], Co-Cr [9], and hydroxyapatite [10]. These synthetic scaffolds have been widely used as they eliminate the need for a donor site; thus reducing the risk of complications and lowering the chance of patient infection or device rejection compared to traditional bone grafting [11]. However, conventional synthetic biomaterials have some limitations. Ceramic or polymeric scaffolds for example, exhibit insufficient mechanical properties or tend to undergo slow in vivo degradation [12]. Non- 
degradable metallic biomaterials such as Ti6V4Al, Co-Cr, and stainless steel on the other hand, possess the desired sufficient strength, but often cause stress shielding and undergo corrosion, wear, and debris formation when used long-term [13, 14].

Biodegradable metals such as Mg-based or Fe-based alloys have gained significant attention in recent years due to their degradation characteristics and higher mechanical strength compared to biodegradable polymers and ceramics [15]. 3D printing of biodegradable metals has the potential to deliver patient-specific biodegradable scaffolds to individuals with traumatic injuries. Further, depending on the required properties of the scaffold at different implantation sites, a porous structure of the scaffold can be designed and fabricated by 3D printing to enhance osteogenesis [16]. At the same time, the design can be engineered to specifically load any bone grafting materials, engineered tissues, or drugs [17].

Mg-based alloys have been widely studied for orthopedic and cardiovascular applications. Improving the purity of cast ingots and refining the grain sizes of the alloy by suitable heat treatments and solution treatments allows for controlled corrosion of these Mg-based alloys [18]. Additionally, the use of post-processing methods such as hot extrusion, rolling, and equal channel angular pressing (ECAP) have been proven to improve the corrosion resistance and mechanical strength by refining the microstructure $[19,20]$. Of late, compression screws made of the magnesium-based alloy WE43 have obtained the CE conformity marking approval in Europe, and 26 patients have already been recruited and have participated in a clinical trial [21]. At the same time, human clinical trial of cardiovascular stents is also ongoing in Europe. The potential synergy between biodegradable metals and 3D printing has also initiated much needed research 
in selective laser melting (SLM) to achieve 3D printing of magnesium powder [22]. The high vapor pressure and low melting points of magnesium tend to be major barriers to fabrication of quality parts of accurate dimensions, although lasers can break the oxide layer of magnesium particles effectively leading to fusion and sintering. Indeed, post-processing methods such as hot extrusion, ECAP, or rolling are not applicable for 3D-printed magnesium parts with complex shapes, whereas the microstructure refinement is a key to overcoming the rapid pitting corrosion of magnesium.

Fe-based alloys, on the other hand, tend to degrade too slowly, and thus, research has been focused on increasing the degradation rates. An iron-manganese binary composition was initially introduced as a biodegradable Fe-based alloy with enhanced corrosion rate and reduced ferromagnetic properties [23]. Various alterations of the Fe-Mn system have been since studied. Addition of 6 wt. \% Si in Fe-30 wt. \% Mn has been shown to induce shape memory effect [24]. Moreover, addition of 1 wt.\% of Pd to Fe-10 wt.\% Mn has resulted in a 10-fold faster corrosion compared to low carbon steel [25]. Fe-Pd and Fe-Pt have both also exhibited faster degradation rates compared to pure iron, and also exhibited minimal cytotoxicity in an indirect MTT cytocompatibility test with L-929 and ECV304 cells after 4 days of culture [26]. Fe-W and FeCNT composites have also exhibited no toxicity with L929 and ECV304 cells as well as good hemocompatibility [27]. Fe-Mn-C (-Pd) alloy was developed and evaluated in both in vitro and in vivo conditions $[28,29]$. Unlike in vitro degradation, in vivo degradation of Fe-Mn-C (-Pd) however, resulted in little degradation although no sign of inflammation or local toxicity was reported. Recent literature reports thus suggest that achieving higher degradation rate in the Fe- 
Mn system still remains a major challenge and indeed still poses a primary limitation preventing the development of biodegradable Fe alloys for medical device applications.

Chou et al of the current group previously reported the feasibility of binder-jet 3D printing of a Fe-30 wt.\% Mn binary mixture to fabricate biodegradable scaffolds [30]. Binder-jet 3D printing of the Fe-Mn mixture exhibited micropores with favorable effects on in vitro degradation and cell attachment. A porous structure with an open porosity of $36 \%$ was obtained after sintering of the 3D-printed (3DP) specimens. 3DP Fe-Mn specimens exhibited a significantly higher corrosion rate when compared to pure Fe using potentiodynamic polarization tests due to the perceived porosity induced by 3DP. Cell infiltration was also observed in the open pores of the 3DP Fe-Mn specimens during cytocompatibility tests using the MC3T3-E1 pre-osteoblast cell line.

In the present follow on study, the research was continued and directed towards developing $\mathrm{Fe}-$ (35 - y) wt.\% $\mathrm{Mn}$ - y wt.\% X (X = Ca, Mg, and y =0, 1, 2) alloy employing a CALPHAD theoretical model to predict the alloy composition with enhanced degradation properties. In order to test the hypothesis, the corresponding $\mathrm{Fe}-\mathrm{Mn}-\mathrm{X}$ alloy powders were synthesized using high energy mechanical alloying (HEMA), and evaluated for their degradation properties and cytocompability. Furthermore, Fe-35 wt.\% Mn and Fe-34 wt.\% Mn-1 wt.\% Ca were selected for 3D printing study based on their cytocompatibility and degradation characteristics. These 3Dprinted specimens were evaluated to confirm if the enhanced degradation and cytocompatibility characteristics observed following milling and conventional sintering are indeed maintained after 3D printing. 


\subsection{Materials and Methods}

\subsection{Methodology for CALPHAD studies}

To evaluate the effect of different alloying elements on the corrosion stability of the alloys, a prior study was conducted that focused on evaluating of the thermodynamic driving force of the overall hydrolysis reaction of magnesium and its alloys in pure water [31]. Using the Density Functional Theory (DFT) approach, the first-principles calculation was focused on a change in enthalpy $\delta \Delta$ HRdop in their actual in order to assess whether the alloying element retard $(\delta \Delta$ HRdop $>0)$ or promote $(\delta \Delta$ HRdop $<0)$ the corrosion process.

Accordingly, in the current study, the same criterion was employed for evaluation of the corrosion stability of $\mathrm{Fe}-35$ wt.\% Mn alloys doped with small amounts of $\mathrm{Ca}$ and $\mathrm{Mg}$. In essence, the following two aqueous reactions were considered; the Gibbs free energy $\Delta \mathrm{GR}$ was calculated for each reaction and the difference between them $(\delta \Delta \mathrm{GR})$ was plotted as a function of the chemical composition of the materials.

$\mathrm{Fe}(\mathrm{s})+2 \mathrm{H}_{2} \mathrm{O}(\mathrm{l})=>\mathrm{Fe}(\mathrm{OH})_{2}(\mathrm{~s})+\mathrm{H}_{2}(\mathrm{~g})$

$[\mathrm{Fe}-\mathrm{Mn}-\mathrm{Ca} / \mathrm{Mg}](\mathrm{s})+2 \mathrm{H}_{2} \mathrm{O}(\mathrm{l})=>[\mathrm{Fe}-\mathrm{Mn}-\mathrm{Ca} / \mathrm{Mg}](\mathrm{OH})_{2}(\mathrm{~s})+\mathrm{H}_{2}(\mathrm{~g})$

Reaction (1) is the hydrolytic reaction of pure Fe in water, while reaction (2) represents the same process for the various considered Fe-based alloys.

The thermodynamic software Thermo-Calc [32] has been employed to conduct the calculations using the SSUB4 database for chemical substances such as oxides, hydroxides and gas phases [33], and TCFE7 for the solid $\mathrm{Fe}-\mathrm{Mn}-\mathrm{Ca} / \mathrm{Mg}$ alloy phases [34]. All the calculations have thus been conducted at temperature of $\mathrm{T}=370{ }^{\circ} \mathrm{C}$ and pressure $\mathrm{P}=1 \mathrm{~atm}$. To overcome the substantial computing resources associated with the first-principles study of the thermodynamic 
parameters of the hydrolytic reactions, the less physically-grounded but yet much more efficient CALPHAD technique [35] was used.

\subsection{Powder preparation}

Pure iron powder (Alfa Aesar, spherical, < $10 \mu \mathrm{m}, 99.9 \%$ ), pure manganese powder (Alfa Aesar, $<10 \mu \mathrm{m}, 99.6 \%$ ), and pure calcium granules (Alfa Aesar, 99.5\%, -16 mesh) were used to synthesize the $\mathrm{Fe}-(1-\mathrm{y})$ wt.\% $\mathrm{Mn}-\mathrm{y}$ wt.\% X (X= Ca, $\mathrm{Mg}$, and y = 0, 1, 2) alloy powders. The milling balls and pure elemental powder mixtures were weighed at a mass ratio of 10:1 and subjected to high energy mechanical alloying (HEMA). The milling vial was sealed under ultrahigh purity (UHP) argon atmosphere within a glove box in order to prevent any oxide formation. A P5 planetary mill (Fritsche, Idar-Oberstein, Germany) was used to perform up to $16 \mathrm{~h}$ of dry milling followed by $8 \mathrm{~h}$ of wet milling cycles using toluene as the wet milling medium. The Febased alloy powder following milling was then collected and sieved using -325 mesh. The alloyed powders collected were subjected to scanning electron microscopy analysis (SEM; JSM6610, JEOL, Tokyo, Japan) to assess the particle morphology. Phase analysis was performed using X-ray diffraction employing X'pert Pro system (Philips, Netherlands) equipped with CuK $\alpha$ radiation $(\lambda=1.5418 \AA$ ) and Si-detector (X'celerator) operated at $45 \mathrm{kV}$ and $40 \mathrm{~mA}$.

\subsection{D parts fabrication}

Solid 3D constructs were fabricated using two methods: cold isostatic pressing (CIP) followed by sintering and binder-jet 3D printing followed by also binder burn out and subsequent sintering in order to study the effect of $\mathrm{Ca}$ and $\mathrm{Mg}$ addition on the degradation properties of the $\mathrm{Fe}-\mathrm{Mn}$ system. The mechanically alloyed powders were consolidated using cold isostatic pressing (CIP) followed by sintering at $1200{ }^{\circ} \mathrm{C}$ in the presence of ultra-high purity (UHP) argon that has been subjected through an oxygen gathering agent to further purify the atmosphere. Further studies 
were conducted using mechanically milled Fe-Mn and Fe-Mn-1Ca powders selected to fabricate the 3D printed specimens using an Ex-Lab machine (The ExOne Company, LLC, North Huntingdon, PA) with a water-based organic binder. The 3D-printed parts were first cured at $200{ }^{\circ} \mathrm{C}$ for $2 \mathrm{~h}$ in air. The cured parts were then heat-treated at, $430{ }^{\circ} \mathrm{C}$ for $0.5 \mathrm{~h}, 620^{\circ} \mathrm{C}$ for $0.5 \mathrm{~h}$, and $1200{ }^{\circ} \mathrm{C}$ for $3 \mathrm{~h}$ in UHP Ar to achieve binder burn-out and subsequent sintering of the FeMn and Fe-Mn-1Ca alloys.

\subsection{Physical properties}

Absolute density of the 3D-printed construct $10 \times 10 \times 4 \mathrm{~mm}$ in dimension, was measured using an AccuPyc II 1340 helium pycnometer (Micromeritics, Norcross, GA) and the envelope density of the 3D-printed constructs was measured using a GeoPyc 1360 (Micromeritics). Using these density measurements, the percent open porosity was calculated using the following equation: Open porosity $(\%)=(($ absolute density - envelope density $) /$ absolute density $) \times 100 \quad$ Eq. 1 Similarly, the percentage shrinkage of 3D-printed components before and after sintering was calculated from the volume of the as measured sintered component by the GeoPyc 1360 and the measured volumes of the components before sintering.

\subsection{Mechanical properties}

Tensile properties measurement of the sintered construct was conducted in accordance with ASTM-E8-04. Bar specimens were printed, cured, sintered, and finally machined into a standard dog-bone shape with a gauge length of $13.5 \mathrm{~mm}$, width of $3 \mathrm{~mm}$, and thickness of $3 \mathrm{~mm}$. Uniaxial tensile testing was performed at room temperature with an Instron machine, using a cross-head speed of $1.3 \mathrm{~mm} / \mathrm{min}$ and a $5 \mathrm{kN}$ load cell. Yield strength (YS), ultimate tensile strength (UTS), Young's modulus (E), and percent elongation (\%) were accordingly determined 
from the stress-strain curves generated from each specimen. Young's modulus was obtained by considering the linear portion of the curves.

\subsection{Electrochemical corrosion test}

Potentiodynamic polarization testing was conducted to assess the degradation rates of all the compacted and printed 3D constructs following sintering. The specimens, with a surface area of $\sim 0.5 \mathrm{~cm}^{2}$, were connected to a copper wire using a silver epoxy and finally mounted in epoxy resin. The mounted samples were mechanically polished with an increasingly small abrasive size up to $1 \mu \mathrm{m}$, sonicated in isopropyl alcohol, and air dried. Exposed surface area was measured by scanning each specimen and analyzing the scanned image using ImageJ software. An electrochemical workstation (CHI 604A, CH Instruments, Inc., Austin, TX) was employed to conduct the test with three-electrode cell setup utilizing platinum as the counter-electrode, $\mathrm{Ag} / \mathrm{AgCl}$ as the reference electrode and the epoxy-mounted sample as the working electrode. The test was performed using Hank's Balanced Salts Solution (HBSS H1387, Sigma-Aldrich, Canada) with $0.35 \mathrm{~g}^{-1}$ sodium bicarbonate buffer warmed to $37.4{ }^{\circ} \mathrm{C}$ to mimic the physiological conditions. The potentiodynamic polarization behavior of the polished sample was recorded at a scan rate of $1 \mathrm{mVs}^{-1}$. Tafel analysis was used to determine the equilibrium corrosion current, $\mathrm{I}_{\text {corr }}$, and the corrosion potential, $\mathrm{E}_{\mathrm{corr}}$, obtained as the intersection of the linearly fitted cathodic and anodic branches of the generated Tafel plot.

\subsection{Immersion corrosion test}

Immersion corrosion measurement was performed using the methods reported in ASTM-G-3172. 3DP Fe-Mn and Fe-Mn-Ca with dimensions of $5 \mathrm{~mm}$ X 5mm X 5mm were mechanically polished up to 1200 grit, ultrasonically cleaned with isopropyl alcohol, and sterilized under UV for $30 \mathrm{~min}$ each side. The sample's weight and surface area were measured recorded before 
immersing the samples in the solutions. The specimens were immersed using a fishing line in Hank's Balanced Salts Solution (HBSS H1387, Sigma-Aldrich, Canada) with 0.35 g 1-1 sodium bicarbonate buffer at temperature of $37.4^{\circ} \mathrm{C}$ in the air atmosphere. After 28 days, the 3D printed samples were removed from the test tubes. The corrosion products were removed in accordance with ASTM G1-03 by immersing the specimens for $30 \mathrm{~min}$ at $80-90{ }^{\circ} \mathrm{C}$ in a solution prepared by using $5 \%$ of sodium hydroxide $(\mathrm{NaOH}), 20 \%$ granulated zinc and $75 \%$ reagent water. The weight loss was then converted by applying the following equaction,

$\mathrm{CR}=\frac{\mathrm{K} \Delta w}{A t D}$

where $\mathrm{CR}$ is the corrosion rate(mm/year), $\mathrm{K}$ is the conversion coefficient $\left(\mathrm{K}=8.76 \times 10^{4}\right.$ $\mathrm{mm} /$ year $), \Delta \mathrm{w}$ is the difference of weight before and after immersion $(\mathrm{g}), \mathrm{A}$ is the initial surface exposed to corrosion $\left(\mathrm{cm}^{2}\right), \mathrm{D}$ is the density of the material $\left(\mathrm{g} \mathrm{cm}^{-3}\right)$ and $\mathrm{t}$ is the immersion time (h).

\subsection{Live/dead direct cell viability assay}

To evaluate the direct cell cytotoxicity of the 3D constructs, the murine osteoblast-like cell line, MC3T3 (ATCC, Rockville, MD), was cultured on the surface of the 3D-printed plate specimens. The 3D-printed specimens with dimensions of $10 \times 10 \times 1 \mathrm{~mm}$ were polished up to 1200 grit using $\mathrm{SiC}$ paper, sonicated in isopropyl alcohol, and sterilized using UV radiation for $30 \mathrm{~min}$. Modified Eagle's medium alpha ( $\alpha$ MEM) supplemented with $10 \% \mathrm{FBS}, 100 \mathrm{U} \mathrm{ml}^{-1}$ penicillin and $100 \mu \mathrm{g} \mathrm{ml}-1$ streptomycin was used as culture medium. MC3T3 cells were seeded onto specimen surfaces at cell density of $4 \times 104$ cells ml $^{-1}$ and incubated at $37.4{ }^{\circ} \mathrm{C}$ in a humidified atmosphere with $5 \% \mathrm{CO}_{2}$. After $72 \mathrm{~h}$ of incubation, cell cytotoxicity was assessed by performing live/dead cell viability assay using commercially available kit (Invitrogen Corporation, Karlsruhe, 
Germany) following the manufacturer's protocol. During the assay, the live and dead cells were stained using ethidium homodimer-1 and calcein-AM respectively, which exhibits live cells as green and dead cells as red under fluorescence imaging at the excitation wavelength of 495 and $528 \mathrm{~nm} \mathrm{~s}$. After the assay, the cells were fixed by immersing the specimens with cells in $2.5 \%$ glutaraldehyde for 15 min followed by dehydration steps subsequently in 70, 80, 90, 95 and 100\% diluted ethanol for 15 min each. Specimens with fixed cells were then air-dried and imaged using scanning electron microscopy.

\subsection{Indirect MTT cell cytotoxicity assay}

MC3T3 cells were also used to assess the in vitro cytotoxicity of the extract media prepared by immersing the 3D-printed specimens in culture medium. Modified Eagle's medium alpha $(\alpha \mathrm{MEM})$ with $10 \% \mathrm{FBS}, 100 \mathrm{U} \mathrm{ml}^{-1}$ penicillin and $100 \mu \mathrm{g} \mathrm{ml}^{-1}$ streptomycin was used as this cell culture media. Prior to the extract media preparation, the 3D-printed specimens were fabricated to have dimensions of $10 \times 10 \times 4 \mathrm{~mm}$ and polished up to 1200 grit to match the surface finish used in live/dead direct cell viability testing. The ratio of culture media volume to specimen weight was maintained at $1 \mathrm{~mL}$ to $0.2 \mathrm{~g}$, according to EN ISO 10993:12. After $72 \mathrm{~h}$ incubation, the extract media was filtered using $0.2 \mu \mathrm{m}$ membrane and this filtered extract was designated as $100 \%$ extract. The $100 \%$ extract was then subjected to inductively coupled plasma - optical emission spectroscopy (ICP-OES) to measure the chemical concentration of Fe, Mn, and Ca. For this analysis, $100 \%$ extract was then further diluted to 50\%, 25\%, and $10 \%$ extract solutions. MC3T3 cells were seeded in a 96-well plate with a cell density of 6,000 cells per well. After $24 \mathrm{~h}$ of incubation, the culture media was replaced with the $100 \%, 50 \%, 25 \%$, and $10 \%$ extract media and cells were further incubated for $72 \mathrm{~h}$. Vybrant MTT Cell Proliferation Kit (Invitrogen Corporation, Karlsruhe, Germany) was used to assess the cytotoxity of the extract 
media. After $72 \mathrm{~h}$ culture, the extract media was replaced with fresh culture media to prevent any interaction between the metal ions and 3-(4,5-dimethylthiazol-2-yl)-2,5-diphenyltetrazolium bromide (MTT). $12 \mathrm{mM}$ MTT in phosphate buffered saline (PBS) was diluted 10x using culture media and $110 \mu \mathrm{L}$ of diluted MTT solution was added to each well for $4 \mathrm{~h}$ of incubation. Formazan crystal was solubilized using sodium dodecylsulfate-hydrochloric acid solution solution, incubated for $12 \mathrm{~h}$, and analyzed at a wavelength of $570 \mathrm{~nm}$ using Synergy 2 microplate reader (BioTek Instruments, Winooski, VT). Furthermore, in order to check the tolerance of metal ion contents from the Fe alloys' degradation products, $0.1,1$, and $10 \mathrm{mM}$ of Fe, Mn, and Ca were prepared by dissolving their chlorides in culture media, applied to MC3T3-E1 cells for 7 days, and followed by MTT assay.

\subsection{Statistical analysis}

Statistical analysis was performed using IBM SPSS Statistics 22.0 (SPSS Inc., Chicago, IL). Average and standard deviations of these 3 sample measurements are reported for mechanical properties and immersion corrosion rates of 3DP specimens. T-test was used to determine any significant mean differences with a p-value of less than 0.05. Averages and standard deviations of the 4 sample measurements were accordingly reported for potentiodynamic polarization measurements. Averages and standard deviations of 3 sample measurements were reported for the MTT cell viability results and two-way ANOVA with Tukey's post-hoc test was used to determine any significant mean differences with a p-value less than 0.05 .

\section{Results}

3.1 Theoretical and experimental approaches to develop degradable Fe-based powder alloys 


\section{CALPHAD results}

Computational study was conducted to evaluate the effects of $\mathrm{Ca}$ and $\mathrm{Mg}$ on the corrosion behavior of Fe-Mn alloy. Accordingly, the following compositions were chosen for the computational study: $\mathrm{Fe}_{65} \mathrm{Mn}_{(35-\mathrm{x})}(\mathrm{Ca} / \mathrm{Mg})_{\mathrm{x}}$, where $\mathrm{x}$ represents the composition by weigth; $0<\mathrm{x}<5 \mathrm{wt} . \%$. Hydrolysis of pure Fe has been accordingly considered as the reference point.

The resulting dependence of $\delta \Delta \mathrm{GR}$ on chemical composition of the Fe-Mn alloys is shown in Figure 1. On this graph, the hydrolysis of pure Fe is set at zero energy and the $\Delta$ GR for all the alloys considered will be calculated in comparison with $\triangle \mathrm{GRFe}$ for pure Fe. A horizontal dashed line at $-42.0 \mathrm{~kJ} / \mathrm{mol}$ denotes the $\delta \Delta \mathrm{GR}$ for the $\mathrm{Fe}_{65} \mathrm{Mn}_{35}$ reference alloy composition.

Two lines with a negative slope in reference to the Fe and Fe-Mn alloys represent the $\delta \Delta \mathrm{GR}$ for Fe-Mn alloys doped with $\mathrm{Ca}$ and $\mathrm{Mg}$. Both elements when added to the Fe-Mn alloy result in increase in the overall thermodynamic stimulus for the corresponding hydrolysis reaction, although to different extents. The oxides and hydroxides of both $\mathrm{Ca}$ and $\mathrm{Mg}$ are known to be more stable than that of $\mathrm{Mn}$ and thus, the partial substitution of $\mathrm{Ca}$ and $\mathrm{Mg}$ for $\mathrm{Mn}$ in $\mathrm{Fe}$ Mn alloy leads to more negative $\delta \Delta \mathrm{GR}$, in turn leading to lower stability of the Fe-Mn-Ca/Mg alloys compared to undoped Fe-Mn suggesting the potential of the $\mathrm{Ca} / \mathrm{Mg}$ alloyed $\mathrm{Fe}-\mathrm{Mn}$ alloys to be more preferable for use in biological implant systems than pure Fe and Fe-Mn alloys.

Based on the above analysis, it can be construed that the results shown in Figure 1 are indicative of the corrosion rate of $\mathrm{Fe}-\mathrm{Mn}$ further alloyed with $\mathrm{Ca}$ and $\mathrm{Mg}$ to be expectedly higher than the rate of unalloyed, pure Fe-Mn alloys. Further alloying or substituting with $\mathrm{Mg}$ has a stronger effect on the corrosion rate than adding $\mathrm{Ca}$, as seen by the higher corrosion rate of the $\mathrm{Mg}$ substituted alloy compared to the same weight fraction of Ca. Although this computational study considers only thermodynamic aspects of the hydrolysis without taking into account any 
kinetic parameters of the process, these qualitative results are in excellent agreement with experimental measurements of the corrosion rates of the alloy materials as will be shown in subsequent sections of the present manuscript.

\section{Powder Synthesis}

Figure 2 exhibits the X-ray diffraction pattern patterns collected on the as-milled Fe-Mn-Ca and Fe-Mn-Mg alloy powders. Binary Fe-Mn alloys are known to consist of the $\gamma$-phase austenite and $\varepsilon$-phase martensite phases [36]. Mechanically alloyed Fe-Mn also exhibited the $\gamma$ - and $\varepsilon$-phase in the diffraction pattern. No undesired or secondary phase/es were observed as an effect of introducing $\mathrm{Ca}$ and $\mathrm{Mg}$ into the Fe-Mn solid solution. Distinct peaks of pure $\mathrm{Ca}$ or $\mathrm{Mg}$ were also not observed in the Fe-Mn-2Ca or Fe-Mn-2Mg alloy composition prepared by HEMA. Homogeneous solid solutions of Fe-Mn-Ca and Fe-Mn-Mg alloy powders were thus obtained or it is also possible that the amount of $\mathrm{Ca}$ and $\mathrm{Mg}$ added were below the limit of $\mathrm{X}$-ray detection favoring the corrosion of the system as discussed later. In the x-ray diffraction patter, addition of $\mathrm{Ca}$ and $\mathrm{Mg}$ exhibited peak shifts indicating possible lattice deviations from the parent structure, indicative of incorporation of $\mathrm{Ca}$ into the Fe-Mn lattice. The alloys were thus subjected to further in vitro assessment as well as mechanical testing and microstructure evaluation.

\section{Electrochemical corrosion of compacted samples}

The potentiodynamic polarization behavior of sintered Fe-Mn, Fe-Mn-Ca, and Fe-Mn-Mg compacted pellet was recorded at a scan rate of $1 \mathrm{mVs}^{-1}$ and the corresponding Tafel plots are shown in Figure 3. The representative curve for each group of alloy was based on the average corrosion potential and current density registered after testing multiple samples $(\mathrm{N}=4)$. The Tafel plots were used to determine the corrosion current density, corrosion potential, and corrosion rate. Average values of these calculations are tabulated in Table 1. Addition of Ca or 
$\mathrm{Mg}$ to the Fe-Mn alloys increased the current density to shift toward the positive side. The corrosion current density of the alloys increased from $1.00 \mu \mathrm{A} \mathrm{cm}^{-2}$ to $2.12 \mu \mathrm{A} \mathrm{cm}^{-2}$ and $6.36 \mu \mathrm{A}$ $\mathrm{cm}^{-2}$ after replacing 1 and 2 wt. \% of Mn with Ca respectively. Similarly, by introducing $\mathrm{Mg}$ into the solid solution, the corrosion current density was increased from $1.00 \mu \mathrm{A} \mathrm{cm}^{-2}$ to $5.89 \mu \mathrm{A} \mathrm{cm}^{-}$ ${ }^{2}$ and $9.16 \mu \mathrm{A} \mathrm{cm}^{-2}$ after replacing 1 and 2 wt. \% of Mn. Corrosion current density is linearly correlated with a corrosion rate, and an increase in corrosion current density implies higher corrosion rate. However, interestingly, the corrosion potential of Fe-Mn-Mg was significantly increased suggesting that the alloy was likely more stable than the binary Fe-Mn alloy. Therefore, based on the electrochemical corrosion result, the Fe-Mn and Fe-Mn-1Ca alloys were selected to investigate the effect of $\mathrm{Ca}$ addition on corrosion, mechanical and cytocompatibility properties of 3D printed specimens of the alloys.

\section{Live/dead cell viability of compacted samples}

Fluorescent images of the live/dead assay are obtained, as shown in Figure 4, after 1 and 3 days of culturing osteoblastic MC3T3-E1 cells on the sintered pellets of Fe-Mn, Fe-Mn-Ca, and Fe$\mathrm{Mn}-\mathrm{Mg}$ alloy powders. Live cells are represented by the fluorescent green, as a result of the intracellular conversion of calcein-AM to calcein. Dead cells are indicated by the glowing red fluorescence due to the compromised cell membrane that permits binding of nucleic acid with ethidium D-1. More live cells were observed in the fluorescent images collected after 3 days compared to the images after 1 days. Both Fe-Mn-1Ca and Fe-Mn-2Ca exhibited more live cells compared to Fe-Mn or Fe-Mn-Mg specimens suggesting the likely better cytocompatibility of incorporating $\mathrm{Ca}$ into the $\mathrm{Fe}-\mathrm{Mn}$ alloy system in comparison to introduction of $\mathrm{Mg}$.

\subsection{D printing of Fe-based powder and in vitro assessment}

Fabrication of $3 D$ printed constructs 
In order to validate the effect of adding $\mathrm{Ca}$ on 3D printing, Fe-Mn and Fe-Mn-1Ca alloy powders were chosen for comparison. This selection was based on the good cytocompatibility exhibited by the sintered Fe-Mn-Ca pellets compared to the Fe-Mn-Mg pellets as discussed above. Hence, 3D printing of Fe-Mn and Fe-Mn-1Ca alloy powder was performed using the binder-jet 3D printing approach. SEM images of both, the initial alloy powder and sintered 3D printed specimens were obtained as shown in Figure 5. Fe-Mn and Fe-Mn-1Ca alloy powders are observed in various sizes with diameters between $5-30 \mu \mathrm{m}$. Micro pores in the range of $\sim 5 \mu \mathrm{m}$ diameter are shown on the surface of the sintered Fe-Mn and Fe-Mn-Ca specimens. The absolute and envelop density measurement results are tabulated in Table 2. Higher shrinkage and lower open porosity after sintering was observed for Fe-Mn compared to Fe-Mn-1Ca. The SEM images also confirm the particle-particle diffusion after sintering the 3D-printed specimens for both, the Fe-Mn and Fe-Mn-Ca constructs, although some differences in densification occurred during the sintering process. Hermawan et al reported the density of Fe-Mn alloy as $7.63 \mathrm{~g} \mathrm{~cm}^{-3}$ [23] and the absolute density of 3DP Fe-Mn was measured as $7.73 \mathrm{~cm}^{-3}$. Hence, the density of 3DP FeMn comparable to that of bulk Fe-Mn alloy indicates that the sintering process of 3DP specimens was achieved with minimal closed porosity and oxide formation. The 3D-printed specimens were further evaluated for their degradation, cytotoxicity, and mechanical properties.

\section{In vitro corrosion measurement of $3 D$ printed specimens}

Tafel plots of the 3D-printed Fe-Mn, and Fe-Mn-1Ca objects were obtained by scanning at the rate of $1 \mathrm{mVs}^{-1}$, as shown in Figure 6. A representative curve is shown for each group based on the average corrosion potential and current density after testing multiple samples $(\mathrm{N}=4)$. Tafel plots were used to determine the corrosion current density, corrosion potential, and corrosion rate and the average values are tabulated in Table 3. Porous morphology of the 3D-printed specimens 
was not considered for these calculations, instead the nominal surface area was used to calculate the corrosion current density. Corrosion potential of Fe-Mn, and Fe-Mn-1Ca was accordingly $0.64 \mathrm{~V}$, and $-0.63 \mathrm{~V}$, respectively indicating the higher thermodynamic corrosion propensity of Fe-Mn alloy similar to the CIP derived systems discussed earlier. The corrosion current density of 3D-printed Fe-Mn-1Ca was determined to be $2.88 \mu \mathrm{A} / \mathrm{cm}^{2}$ (Table 3), that is slightly improved from the corrosion current density of the compacted Fe-Mn-1Ca determined to be $2.12 \mu \mathrm{A} / \mathrm{cm}^{2}$ (Table 1) and that of the 3D printed Fe-Mn corrosion current density of $2.21 \mu \mathrm{A} / \mathrm{cm}^{2}$ (Table 3). The corrosion rates of 3DP Fe-Mn and Fe-Mn-1Ca is determined to be 0.04 and $0.07 \mathrm{~mm} / \mathrm{year}$ respectively according to Faraday's Law.

Figure 7 presents the surface morphology after the potentiodynamic polarization test of 3DP Fe-Mn and Fe-Mn-1Ca. Exposed surface areas of both samples exhibited different pore sizes. Although nominal surface area is used to calculate the corrosion current density tabulated in Table 3, the actual surface area exposed for the test can be larger due to the porosity of 3DP Fe-Mn and Fe-Mn-1Ca. Corrosion pits were observed on the surface of both the samples. The insoluble degradation products corresponded mainly to iron and manganese oxides that are formed inside of the micropores as confirmed by EDAX elemental analysis shown in Figure 7.

In order to supplement the electrochemical corrosion result, immersion corrosion measurement was performed. The average weight loss of 3DP Fe-Mn and Fe-Mn-Ca specimens, after the immersion in HBSS for 28 days, is displayed in Figure 8. The average corrosion rate of 3DP Fe-Mn and Fe-Mn-Ca was calculated to be 0.03 and $0.14 \mathrm{~mm} / \mathrm{year}$ respectively. As seen in the electrochemical corrosion measurement, the immersion corrosion rate of 3DP Fe-Mn-Ca was larger than that of 3DP Fe-Mn, and a larger difference between these values was also observed.

\section{In vitro cytoxicity test of $3 D$ printed specimens}


Fluorescent images of live/dead cell viability assay are presented in Figure 9 to assess the cytotoxicity of the 3D-printed Fe-Mn and Fe-Mn-1Ca alloys. After 1 and 3 day cultures, 3Dprinted Fe-Mn and Fe-Mn-1Ca specimens exhibited live cell viability comparable to the tissue culture plastic control. Figure 10 exhibits the cell morphology after fluorescent imaging of the live/dead cell viability assay. Substantial cell-cell junctions and cytoplasmic extension of MC3T3 cells was observed on the 3D-printed Fe-Mn and Fe-Mn-1Ca specimens as shown in Figure 10.

The indirect cytotoxicity test result was plotted in Figure 11 representing the corrosion extracts derived from the 3D-printed Fe-Mn, and Fe-Mn-1Ca samples. After 3 days of culturing the MC3T3-E1 cells in 100\% extract, the cell viability assessed using MTT cytoxicity test exhibited in excess of $80 \%$ of cell viability, with respect to negative control of cell culture plastic. Cell viability of 50,25 , and $10 \%$ extract media diluted with fresh media exhibited $\sim 100 \%$ cell viability for both alloy systems. In contrast to the live/dead assay result, no significant difference in cell viability was observed among the different groups. According to ISO protocol for cytotoxicity testing, a $75 \%$ or higher cell viability is generally considered a good representation of non-toxicity [37]. Thus, good cell viability of both the 3D-printed Fe-based alloy samples is demonstrated using indirect MTT cytotoxicity test. Similar Fe and Mn compositions were observed in the extract media collected for both, Fe-Mn compared to Fe-Mn-1Ca, while a relatively higher $\mathrm{Ca}$ concentration compared to its nominal composition in the $\mathrm{Fe}-\mathrm{Mn}-1 \mathrm{Ca}$ alloy was observed as shown in Table 4 indicating the higher corrosion propensity of the Fe-Mn-1Ca alloy system.

Figure 12 illustrates the cell viability of $0.1,1$, and $10 \mathrm{~m} \mathrm{~mol} \mathrm{of} \mathrm{FeCl}_{2}, \mathrm{MnCl}_{2}$, and $\mathrm{CaCl}_{2}$, respectively dissolved in the culture media after 7 days culture. Cell viability higher than $75 \%$ 
was maintained for $\mathrm{Fe}$ and $\mathrm{Mn}$ at concentrations up to $1 \mathrm{mM}$. On the other hand, as expected, $\mathrm{Ca}$ and $\mathrm{Mg}$ exhibited no cytotoxicity at $10 \mathrm{mM}$, although higher concentrations of $\mathrm{Ca}$ and $\mathrm{Mg}$ were not tested for this study.

\section{Mechanical properties}

Stress-strain curves, shown in Figure 13, represents the tensile properties of 3D-printed Fe-Mn, and Fe-Mn-1Ca after sintering. Ultimate tensile strength (UTS), yield strength (YS), elongation (E) and Young's modulus of 3D-printed specimens are tabulated in Table 5. 3D printed Fe-Mn exhibited: UTS of 228.1 MPa, YS of $189.7 \mathrm{MPa}$, and modulus of $39 \mathrm{GPa}$. Addition of Ca to Fe-Mn alloy resulted in higher stiffness which increased UTS from 228.1 to 296.6 $\mathrm{MPa}$, and modulus from 39 to $163 \mathrm{GPa}$. However, brittle fracture without any elastic to plastic deformation yielding was observed in the stress-strain curve of the 3D printed Fe-Mn-1Ca and thus the elongation observed at fracture was only $\sim 0.1 \%$ as opposed to $\sim 1.5 \%$ for Fe-Mn.

\subsection{Discussion}

\subsection{Alloying strategy}

Various alloying elements or composite materials have been explored to improve the degradation rate of biodegradable Fe-based alloys. The strategy has been to introduce noble metals as alloying elements such as $\mathrm{Pd}, \mathrm{Pt}, \mathrm{Au}, \mathrm{Ag}$ as well as inert refractory elements such as W including group IV common elements such as Si. These elements tend to act as galvanic corrosion couples with Fe matrices resulting in enhanced degradation [26, 27, 38, 39]. The noble element precipitates can be removed from the implantation site if the biodegradable Fe alloyed with these alloying elements are used for cardiovascular applications. On the contrary, limited amount of blood and fluid exchange occurs in the areas associated with cranio-maxillofacial bone defects. 
Among recently published in vivo studies of biodegradable Fe-based alloys, rat femoral implantation of pure $\mathrm{Fe}, \mathrm{Fe}-10 \mathrm{Mn}-1 \mathrm{Pd}$, and $\mathrm{Fe}-21 \mathrm{Mn}-0.7 \mathrm{C}-1 \mathrm{Pd}$ pins were used to assess the degradation and biocompatibility of the Fe alloys in bone tissue for up to 52 weeks [29]. Very little degradation was however, observed and hence, consequently, no sign of toxicity was observed in the CT analysis and histology of the surrounding tissue. Further analysis also showed that the in vitro degradation rate of $\mathrm{Fe}-21 \mathrm{Mn}-0.7 \mathrm{C}-1 \mathrm{Pd}$ alloy was reported to be $\sim 0.13 \mathrm{~mm} /$ year [28]. All of the alloying elements considered are known to be inert or belong to the precious metal category, the dissolution of which is hardly likely which is also justifiably indicated by the in vivo reports. Drynda et al. reported that the biodegradable Fe-based alloys form insoluble protection layer that inhibits further degradation the alloy in biological medium [40]. Therefore, in the present study, less corrosion resistant alloying elements, $\mathrm{Ca}$ and $\mathrm{Mg}$, that are known to be highly reactive to aqueous environments and correspondingly known to induce higher corrosion to the corrosion resistant Fe system were employed such that these alloys could result in faster degradation from the scaffold prior to the Fe-Mn matrix.

Melting points of both $\mathrm{Ca}\left(842^{\circ} \mathrm{C}\right)$ and $\mathrm{Mg}\left(650^{\circ} \mathrm{C}\right)$ are low compared to that of $\mathrm{Fe}$ $\left(1538{ }^{\circ} \mathrm{C}\right)$ and $\mathrm{Mn}\left(1246{ }^{\circ} \mathrm{C}\right)$. Due to this extreme difference in the melting points of $\mathrm{Fe}$ and $\mathrm{Mn}$ versus $\mathrm{Ca}$ and $\mathrm{Mg}$, traditional gas-atomization of the alloy powders is unable to achieve the homogeneous solid solution of the nominal composition. High energy mechanical alloying (HEMA) was therefore used to synthesize Fe-Mn-Ca and Fe-Mn-Mg since Ca and $\mathrm{Mg}$ do not have solubility in Fe or Mn. HEMA can however, enable the rapid diffusion of $\mathrm{Ca}$ and $\mathrm{Mg}$ into the deformed lattice of the Fe-Mn alloy leading to metastable solid solutions of Fe-Mn-Ca and $\mathrm{Fe}-\mathrm{Mn}-\mathrm{Mg}$ systems. Homogeneous alloy powders of Fe-Mn-Ca and Fe-Mn-Mg were therefore accordingly obtained showing no characteristic peaks of pure $\mathrm{Ca}$ or $\mathrm{Mg}$ in the X-ray diffraction 
pattern (Figure 2). Although as mentioned in the results section, the weight percent of the $\mathrm{Ca}$ and Mg considered in this study of 1-2 wt\% could also be below the detection limit of standard X-ray diffraction units.

Binder-jet 3D-printed specimens of different compositions with irregular particle morphology can result in different open porosity. Different open porosity is expected to expose different surface area and affect the corrosion measurement. In order to avoid such inconsistencies, compacted pellets of Fe-Mn-Ca and Fe-Mn-Mg were used for the corrosion assessment to demonstrate the increase in degradation rates with addition of $\mathrm{Ca}$ and $\mathrm{Mg}$ to the Fe-Mn alloys generated by HEMA. The effect of adding $\mathrm{Ca}$ and $\mathrm{Mg}$ was assessed by the potentiodynamic polarization test results showing an increased corrosion current density related to the amount of $\mathrm{Ca}$ and $\mathrm{Mg}$ present in the solid solution as seen in Table 1. However, the average of corrosion potentials slightly shifting to the passive side was observed to conflict with the increase in corrosion current densities of Fe-Mn alloys. Corrosion potential and corrosion current density are thermodynamic and kinetic representation of corrosion, respectively. An increase in corrosion current density and anodic shift of corrosion potential are coherent observations when the corrosion resistance is diminished. In Figure 3, Fe-Mn-Mg exhibited a significant passivation of corrosion potential compared to Fe-Mn and hence, it is unclear to determine that the addition of $\mathrm{Mg}$ enhanced the corrosion of Fe-Mn alloys. On the other hand, the addition of $\mathrm{Ca}$ increased with the corrosion current density without a significant passivation of corrosion potential. Thus, Fe-Mn and Fe-Mn-1Ca were selected for 3D printing studies.

Higher corrosion rate of 3DP Fe-Mn-Ca in comparison to 3DP Fe-Mn, was observed in the potentiodynamic polarization and immersion corrosion. Addition of $\mathrm{Ca}$ also caused higher $\mathrm{Fe}$ concentration in the ICP analysis of the extract media of 3DP Fe-Mn-1Ca compared to 3DP Fe- 
Mn (Table 4) indicating the higher propensity of corrosion for alloy containing $\mathrm{Ca}$. This observation is also correlated with the enhanced degradation properties of the Ca containing alloys due to the presence of $\mathrm{Ca}$ in the solid solution of the Fe-Mn alloy further serving to demonstrate and validate the CALPHAD calculation and the electrochemical corrosion tests.

\subsection{Binder-jet 3D printing}

Binder-jet 3D printing of biodegradable Fe alloys demonstrated the ability to enhance degradation rates due to the higher exposed surface area of the elements in the porous structure. Binder-jet 3D printing results in micropores after sintering due to the low as-printed density [41]. Chou et. al previously demonstrated an increase in degradation properties of Fe-30Mn mixtures after binder-jet 3D printing [30]. Moreover, these micropores create a rough surface finish which can also likely improve osseointegration. For industrial applications, these micropores are typically infiltrated with the same or different material to improve corrosion resistance and mechanical properties. Medical devices, made of inert metals such as titanium, also share the same dilemma requiring infiltration and generating a smooth surface finish to minimize wear related debris formation that is known to create hypersensitivity and possible metallosis [42]. On the other hand, development of a biodegradable Fe-based alloy is focused on increasing the corrosion rate, and it is likely that the micropores induced by binder-jet 3D printing are beneficial to enhance the degradation of biodegradable Fe-based scaffolds.

When the potentiodynamic polarization data of compacted pellets and $3 \mathrm{D}$ printing samples were compared, 3DP samples clearly exhibited increased corrosion current density in both Fe-Mn and Fe-Mn-1Ca alloys (Table 1 and 3). The porous structure of 3DP Fe-Mn and FeMn-1Ca enhanced the degradation rate by exposing a larger surface area to the electrolyte.

Insoluble oxide formation was observed in the micropores of 3DP Fe-Mn and Fe-Mn- 
$1 \mathrm{Ca}$ after the potentiodynamic polarization test (Figure 7). These observations convey that the presence of micropores from binder-jet 3D printing can increase the contact with electrolytes and enhance the degradation of biodegradable Fe-based alloy.

Although both immersion corrosion and electrochemical corrosion measurements showed higher corrosion rate in 3DP Fe-Mn-1Ca compared to 3DP Fe-Mn, the effect of Ca addition on porosity could have affected these measurements. Higher porosity by $13.6 \%$ observed in 3DP Fe-Mn-1Ca must have had higher true surface area compared to 3DP Fe-Mn and hence, resulted in the larger difference in the immersion corrosion rates where all surfaces were exposed to HBSS medium (Figure 8). Ca addition resulted in enhanced degradation by improving the corrosion current density and causing the higher porosity of Fe-Mn alloys. Further research is necessary to understand which factor has more effect on the degradation of 3DP FeMn alloys.

\subsection{Indirect cytocompatibility of biodegradable Fe alloys}

Indirect cytocompatibility of biodegradable Fe alloys has been assessed using various types of cells such as fibroblast, smooth muscle cells, and osteoblasts depending on the target application $[26,27,30]$. In this study, the cytocompatibility of 3DP Fe-Mn and Fe-Mn-1Ca alloys were investigated for their potential use as cranio-maxillofacial implants. Cranio-maxillofacial implants are placed in direct contact with bone tissues within the human body. As the material corrodes within the body, it releases metallic ions which may be harmful to cellular functions. Therefore, degradation products of these implants must be compatible with associated bone cells. For this reason, mouse pre-osteoblast MC3T3-E1 cells were used to test the cytocompatibility of possible implant materials. 
MTT assay results exhibited good cytocompatibility with $100 \%, 50 \%, 25 \%$, and $10 \%$ extract media of 3DP Fe-Mn and Fe-Mn-1Ca, as shown in Figure 11. ICP analysis conducted on the $100 \%$ extract collected exhibited $\sim 5 \mathrm{ppm}$ (equivalent to $\sim 0.1 \mathrm{mM}$ ) Fe and $\mathrm{Mn}$ concentration as well as $\sim 29 \mathrm{ppm}$ (equivalent to $\sim 0.7 \mathrm{mM}$ ) additional calcium concentration in 3DP Fe-Mn$1 \mathrm{Ca}$ extract. Ionic concentration of Fe and other alloying elements in the extract media is closely correlated with the cell viability. Purnama et al. reported the fibroblast cell count after dosing different concentration of $\mathrm{FeCl}_{2}$ and $\mathrm{MnCl}_{2}$ to check the tolerance of fibroblasts against the metal ion concentration [43]. At $25 \mathrm{ppm}$ (equivalent to $\sim 0.5 \mathrm{mM}$ ) of $\mathrm{MnCl}_{2}$ and $150 \mathrm{ppm}$ (equivalent to $\sim 3 \mathrm{mM}$ ) of $\mathrm{FeCl}_{2}$, the fibroblast cell count was halved. Unlike the fibroblast, MC3T3 preosteoblasts tested here indicated that they were cytocompatible with $1 \mathrm{mM}$ concentration of $\mathrm{FeCl}_{2}$ and $\mathrm{MnCl}_{2}$ (Figure 12).

The metal ion concentration from 3DP Fe-Mn and Fe-Mn-1Ca reaches approximately 10\% of tolerable amounts (Table 4 and Figure 12). Hence, higher degradation rates can be pursued by altering the composition in the next development process of the approach and the alloy in future studies. The current results thus indeed demonstrate the promise of the current composition and the binder jet printing approach.

\subsection{Mechanical properties}

Ultimate tensile strength of 3DP Fe-Mn (228.1 MPa) and Fe-Mn-1Ca (296.6 MPa) was higher than that of human cortical bone. 3DP Fe-based medical devices for cranio-maxillofacial application are anticipated to be implanted in semi-loaded or non-load bearing sites. Porous structures of 3DP Fe-Mn-1Ca with 52.9\% open porosity resulted in brittle fracture during tensile testing. Ductility of 3DP Fe-Mn-1Ca however, needs to be improved to qualify for load-bearing bone implant applications that require the constructs to exhibit adequate toughness since both 
strength and ductility are very much needed for the fabrication of tough implants to bear the load and the ensuing energy transmitted to the implants during normal functioning of the patient. 3DP Fe-Mn with $39.3 \%$ open porosity exhibited higher ductility than 3DP Fe-Mn-1Ca; suggesting that less porosity can improve the ductility of 3DP Fe-based alloys. Thus presence of the micropores and the consequence of alloying has a beneficial impact on the corrosion current density and the expected corrosion of the alloy as seen in the in-vitro studies. Further optimization of particle size, binder concentrations, sintering time and environment as well as binder saturation can lead to improved constructs with optimal micropores resulting in improved toughness while also accelerating the corrosion. These studies will be planned in the future. The objectives of the current study was to demonstrate the effects of addition of $\mathrm{Ca}$ and $\mathrm{Mg}$ to generate the new Fe-Mn alloys demonstrating improved corrosion leaving room for future studies to optimize the parameters outlined above. Hermawan et al. reported UTS and elongation at fracture of rolled bulk Fe-35Mn as $550 \mathrm{MPa}$ and $31 \%$ respectively [23], with the significantly higher strength as a result of the near-fully dense material compared to the porous 3DP material reported here. Another option to obtain improved densities without compromising the corrosion current densities reported here is to explore laser and electron beam based approaches. Electron beam-based or laser-based 3D fabrication that represent smaller volume of melted regions subjected to rapid melting and cooling can achieve higher densification and optimal mechanical properties. This is likely possible since these techniques cause instant particle to particle diffusion, melting and subsequent solidification caused by the laser melting and solidification process resulting in likely minimal or no microporosities. Also, 3DP Fe-based alloys can be further infiltrated either with the same material, ceramic or biodegradable polymers to improve the toughness although a decrease in porosity will likely result in a reduction in the 
degradation rate. The use of a degradable polymer or ceramic will likely be preferred since these systems will not likely compromise the degradation rates while enhancing the mechanical properties.

\subsection{Conclusion}

In this study, theoretical calculation was performed to predict the effect of introducing $\mathrm{Ca}$ and $\mathrm{Mg}$ on the corrosion behavior of biodegradable Fe-Mn alloy. Fe-Mn-Ca and Fe-Mn-Mg alloys were accordingly synthesized and the sintered pellets of the alloys were analyzed for their corrosion and cytotoxicity properties. Furthermore, Fe-Mn and Fe-Mn-Ca were selected for binder-jet 3D printing studies. Based on the results, the main conclusions are listed as follows:

(1) CALPHAD calculation exhibited an increase in corrosion rates of binary Fe-35Mn alloy by replacing $\mathrm{Mn}$ content with $\mathrm{Ca}$ and $\mathrm{Mg}$. Synthesized powder of Fe-Mn-Ca and Fe-Mn-Mg exhibited $\gamma$-phase austenite and $\varepsilon$-phase martensite solid solution without the presence of any distinct $\mathrm{Ca}$ or $\mathrm{Mg}$ peaks in X-ray diffraction patterns.

(2) Sintered pellets of Fe-Mn-Ca and Fe-Mn-Mg demonstrated that the corrosion current density increased with $\mathrm{Ca}$ or $\mathrm{Mg}$ content in the potentiodynamic polarization tests validating the theoretical CALPHAD studies. Corrosion potential of Fe-Mn-Mg though significantly shifted to the passive side and hence, Fe-Mn-1Ca was selected for 3D printing study with Fe-Mn.

(3) 3D-printed specimens of Fe-Mn and Fe-Mn-1Ca presented 39.3 and $52.9 \%$ open porosity respectively. Micro pores in size of $\sim 5$ um diameter were observed under scanning electron microscopy.

(4) The corrosion of 3D-printed Fe-Mn and Fe-Mn-1Ca was greater than that of the sintered compacted pellets. Both electrochemical and immersion corrosion measurement exhibited higher corrosion rate of 3D-printed Fe-Mn-1Ca compared to 3D-printed Fe-Mn . 
(5) 3D-printed Fe-Mn and Fe-Mn-1Ca also exhibited good cytocompatibility with MC3T3

cells assessed using both direct live/dead and indirect MTT cell viability assays. In terms of mechanical properties, Fe-Mn-1Ca exhibited higher stiffness and brittle failure in tensile testing but higher UTS was observed in comparison to Fe-Mn.

\subsection{Acknowledgements}

The authors gratefully acknowledge the financial support of America Makes, Grant FA8665012-2-7230. The authors also express their profound gratitude to the financial assistance provided by the U.S. National Science Foundation, Engineering Research Center, Grant \#EEC-0812348. PNK would like to acknowledge the Edward R. Weidlein Chair Professorship funds. Center for Complex Engineered Materials for Multifunctional Materials (CCEMM), Swanson School of Engineering, and University of Pittsburgh is also acknowledged for providing the equipment and infrastructure needed to execute the work described. 


\section{Reference}

[1] David D. Maxillofacial trauma: principles of management, priorities and basic techniques. Trauma 1999;1:215-26.

[2] SCHMITZ JP, Hollinger JO. The critical size defect as an experimental model for craniomandibulofacial nonunions. Clinical orthopaedics and related research 1986;205:299-308.

[3] Hollinger JO, Kleinschmidt JC. The critical size defect as an experimental model to test bone repair materials. Journal of Craniofacial Surgery 1990;1:60-8.

[4] Jacobs JMS, Dec W, Levine JP, McCarthy JG, Weimer K, Moore K, Ceradini DJ. Best Face Forward: Virtual Modeling and Custom Device Fabrication to Optimize Craniofacial Vascularized Composite Allotransplantation. Plastic and Reconstructive Surgery 2013;131:64-70 10.1097/PRS.0b013e3182729ef0.

[5] Ciocca L, Mazzoni S, Fantini M, Persiani F, Marchetti C, Scotti R. CAD/CAM guided secondary mandibular reconstruction of a discontinuity defect after ablative cancer surgery. Journal of Cranio-Maxillofacial Surgery 2012;40:e511-e5.

[6] Eufinger H, Harders A, Heuser L, Kruse D, Machtens E, Wehmoller M. Reconstruction of craniofacial bone defects with individual alloplastic implants based on CAD/CAM-manipulated CT-data. Journal of Cranio-Maxillofacial Surgery 1995;23:175+.

[7] Scolozzi P, Martinez A, Jaques B. Complex orbito-fronto-temporal reconstruction using computer-designed PEEK implant. Journal of Craniofacial Surgery 2007;18:224-8.

[8] Heissler E, Fischer FS, Boiouri S, Lehrnann T, Mathar W, Gebhardt A, Lanksch W, Bler J. Custom-made cast titanium implants produced with CAD/CAM for the reconstruction of cranium defects. International Journal of Oral and Maxillofacial Surgery 1998;27:334-8. [9] Grandfield K, Palmquist A, Gonçalves S, Taylor A, Taylor M, Emanuelsson L, Thomsen P, Engqvist $\mathrm{H}$. Free form fabricated features on $\mathrm{CoCr}$ implants with and without hydroxyapatite coating in vivo: a comparative study of bone contact and bone growth induction. Journal of Materials Science: Materials in Medicine 2011;22:899-906.

[10] Fierz FC, Beckmann F, Huser M, Irsen SH, Leukers B, Witte F, Degistirici Ö, Andronache A, Thie M, Müller B. The morphology of anisotropic 3D-printed hydroxyapatite scaffolds. Biomaterials 2008;29:3799-806.

[11] Younger EM, Chapman MW. Morbidity at bone graft donor sites. Journal of orthopaedic trauma 1989;3:192-5.

[12] Bohner M. Resorbable biomaterials as bone graft substitutes. Materials Today 2010;13:2430.

[13] Jorgenson DS, Mayer MH, Ellenbogen RG, Centeno JA, Johnson FB, Mullick FG, Manson PN. Detection of titanium in human tissues after craniofacial surgery. Plastic and reconstructive surgery 1997;99:976-9.

[14] Zaffe D, Bertoldi C, Consolo U. Accumulation of aluminium in lamellar bone after implantation of titanium plates, Ti-6Al-4V screws, hydroxyapatite granules. Biomaterials 2004;25:3837-44.

[15] Zheng Y, Gu X, Witte F. Biodegradable metals. Materials Science and Engineering: R: Reports 2014;77:1-34.

[16] Karageorgiou V, Kaplan D. Porosity of 3D biomaterial scaffolds and osteogenesis. Biomaterials 2005;26:5474-91.

[17] Hollister SJ. Porous scaffold design for tissue engineering. Nat Mater 2005;4:518-24. 
[18] Song G. Control of biodegradation of biocompatable magnesium alloys. Corrosion Science 2007;49:1696-701.

[19] Yamashita A, Horita Z, Langdon TG. Improving the mechanical properties of magnesium and a magnesium alloy through severe plastic deformation. Materials Science and Engineering: A 2001;300:142-7.

[20] Li ZJ, Gu XN, Lou SQ, Zheng YF. The development of binary Mg-Ca alloys for use as biodegradable materials within bone. Biomaterials 2008;29:1329-44.

[21] Windhagen H, Radtke K, Weizbauer A, Diekmann J, Noll Y, Kreimeyer U, Schavan R, Stukenborg-Colsman C, Waizy H. Biodegradable magnesium-based screw clinically equivalent to titanium screw in hallux valgus surgery: short term results of the first prospective, randomized, controlled clinical pilot study. Biomed Eng Online 2013;12:62.

[22] Giesekel M, Noelkel C, Kaierlel S, Weslingl V, Haferkarnp H. Selective Laser Melting of Magnesium and Magnesium Alloys. Magnesium Technology 2013 2013:65-8.

[23] Hermawan H, Alamdari H, Mantovani D, Dubé D. Iron-manganese: new class of metallic degradable biomaterials prepared by powder metallurgy. Powder Metallurgy 2008;51:38-45.

[24] Liu B, Zheng Y, Ruan L. In vitro investigation of Fe30Mn6Si shape memory alloy as potential biodegradable metallic material. Materials Letters 2011;65:540-3.

[25] Schinhammer M, Hänzi AC, Löffler JF, Uggowitzer PJ. Design strategy for biodegradable Fe-based alloys for medical applications. Acta Biomaterialia 2010;6:1705-13.

[26] Huang T, Cheng J, Zheng Y. In vitro degradation and biocompatibility of Fe-Pd and Fe-Pt composites fabricated by spark plasma sintering. Materials Science and Engineering: C 2014;35:43-53.

[27] Cheng J, Zheng Y. In vitro study on newly designed biodegradable Fe-X composites (X=W, CNT) prepared by spark plasma sintering. Journal of Biomedical Materials Research Part B:

Applied Biomaterials 2013;101:485-97.

[28] Schinhammer M, Steiger P, Moszner F, Löffler JF, Uggowitzer PJ. Degradation performance of biodegradable FeMnC(Pd) alloys. Materials Science and Engineering: C 2013;33:1882-93.

[29] Kraus T, Moszner F, Fischerauer S, Fiedler M, Martinelli E, Eichler J, Witte F, Willbold E, Schinhammer M, Meischel M. Biodegradable Fe-based alloys for use in osteosynthesis: Outcome of an in vivo study after 52weeks. Acta biomaterialia 2014;10:3346-53.

[30] Chou D-T, Wells D, Hong D, Lee B, Kuhn H, Kumta PN. Novel processing of ironmanganese alloy-based biomaterials by inkjet 3-D printing. Acta Biomaterialia 2013;9:8593-603. [31] Velikokhatnyi OI, Kumta PN. First-principles studies on alloying and simplified thermodynamic aqueous chemical stability of calcium-, zinc-, aluminum-, yttrium- and irondoped magnesium alloys. Acta Biomaterialia 2010;6:1698-704.

[32] Andersson JO, Helander T, Hoglund LH, Shi PF, Sundman B. THERMO-CALC \& DICTRA, computational tools for materials science. Calphad-Computer Coupling of Phase Diagrams and Thermochemistry 2002;26:273-312.

[33] Thermo-Calc Software SSUB5 SGTE Substances Database version 5.1, (Accessed 23 Aug 2013).

[34] Thermo-Calc Software TCFE7 Steels/Fe-alloys database version 7, (Accessed 23 Aug 2013).

[35] Saunders N, Miodownik AP. CALPHAD (Calculation of Phase Diagrams): A

Comprehensive Guide: A Comprehensive Guide: Elsevier Science; 1998. 
[36] Lee Y-K, Jun J-H, Choi C-S. Damping Capacity in Fe-Mn Binary Alloys. ISIJ International 1997;37:1023-30.

[37] ISO 10993-5(2009), Biological evaluation of medical devices - Part 5: Tests for in vitro cytotoxicity, International Organization for Standardization.

[38] Huang T, Cheng J, Bian D, Zheng Y. Fe-Au and Fe-Ag composites as candidates for biodegradable stent materials. Journal of Biomedical Materials Research Part B: Applied Biomaterials 2015:n/a-n/a.

[39] Xu Z, Hodgson MA, Cao P. A comparative study of powder metallurgical (PM) and wrought Fe-Mn-Si alloys. Materials Science and Engineering: A 2015;630:116-24.

[40] Drynda A, Hassel T, Bach FW, Peuster M. In vitro and in vivo corrosion properties of new iron-manganese alloys designed for cardiovascular applications. Journal of Biomedical Materials Research Part B: Applied Biomaterials 2015;103:649-60.

[41] Dimitrov D, Schreve K, De Beer N. Advances in Three Dimensional Printing - state of the art and future perspectives. 2006. p. p.21-49.

[42] Hong SB, Eliaz N, Sachs EM, Allen SM, Latanision RM. Corrosion behavior of advanced titanium-based alloys made by three-dimensional printing (3DPTM) for biomedical applications. Corrosion Science 2001;43:1781-91.

[43] Purnama A, Mantovani D, Couet J. Caveolin: A possible biomarker of degradable metallic materials toxicity in vascular cells. Acta biomaterialia 2013;9:8754-60. 


\section{Binder-jetting 3D printing and alloy development of biodegradable Fe- $\mathrm{Mn}-\mathrm{Ca} / \mathrm{Mg}$ alloys}

Daeho Hong ${ }^{1}$, Da-Tren Chou ${ }^{1}$, Oleg I. Velikokhatnyi ${ }^{1}$, Abhijit Roy ${ }^{1}$, Boeun Lee ${ }^{1}$, Isaac Swink ${ }^{4}$, Ilona Issaev ${ }^{5}$, Howard A. Kuhn ${ }^{6}$, and Prashant N. Kumta ${ }^{1,2,3}$

${ }^{1}$ Department of Bioengineering

Swanson School of Engineering, University of Pittsburgh, Pittsburgh, PA 15261

${ }^{2}$ Department of Chemical and Petroleum Engineering

Swanson School of Engineering, University of Pittsburgh, Pittsburgh, PA 15261

${ }^{3}$ Department of Mechanical Engineering and Materials Science

Swanson School of Engineering, University of Pittsburgh, Pittsburgh, PA 15261

${ }^{4}$ Department of Engineering, Robert Morris University, Moon, PA 15108

${ }^{5}$ Department of Mechanical Engineering, Ort Braude College, Karmiel, Israel

${ }^{6}$ ExOne Company, Irwin, PA 15642 


$$
\mathrm{Me}+2 \mathrm{H}_{2} \mathrm{O}=\mathrm{Me}(\mathrm{OH})_{2}+\mathrm{H}_{2}
$$

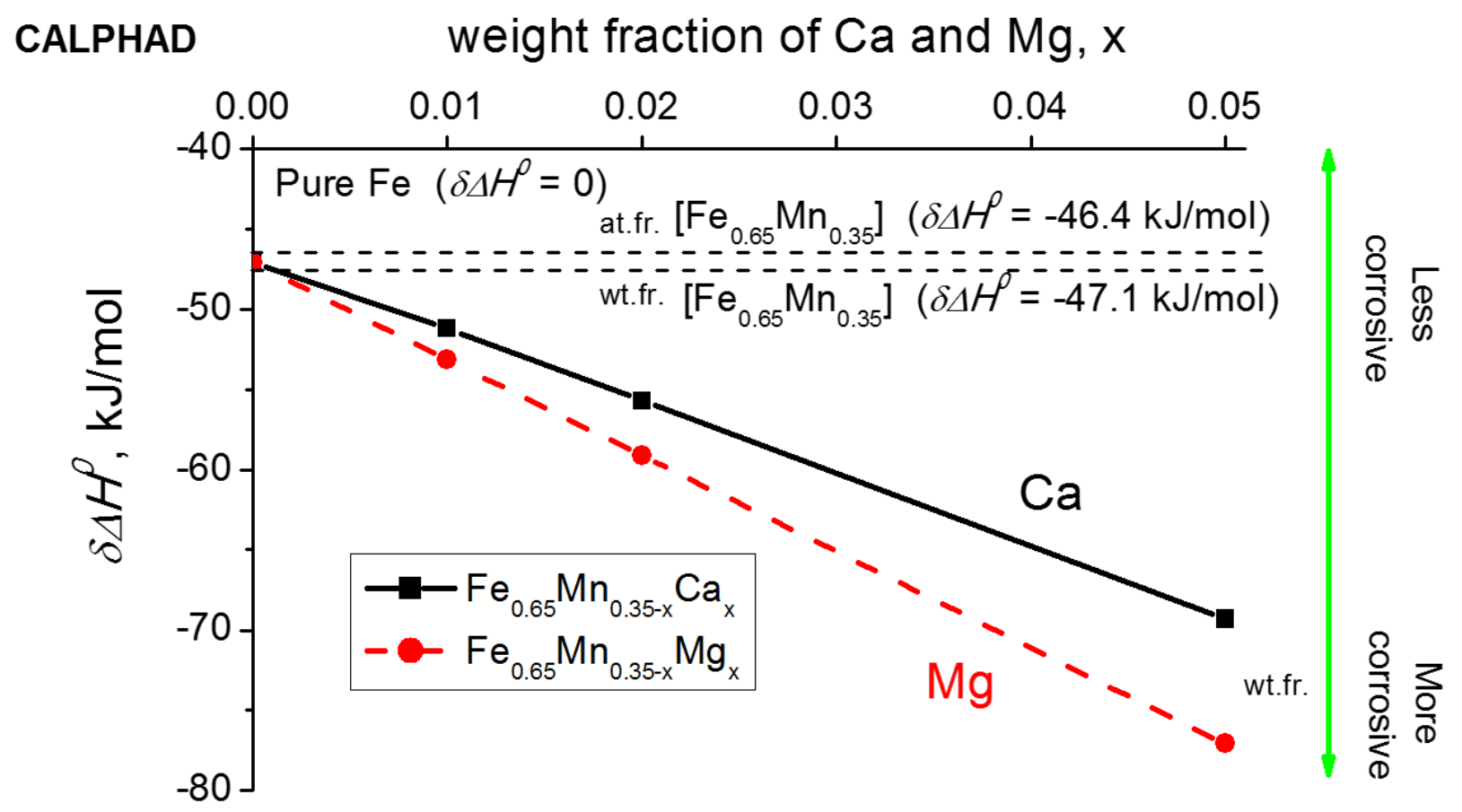

Figure 1. Results of CALPHAD simulations on the effect of adding $\mathrm{Ca}$ and $\mathrm{Mg}$ to binary Fe-Mn alloy for enhanced corrosion. 


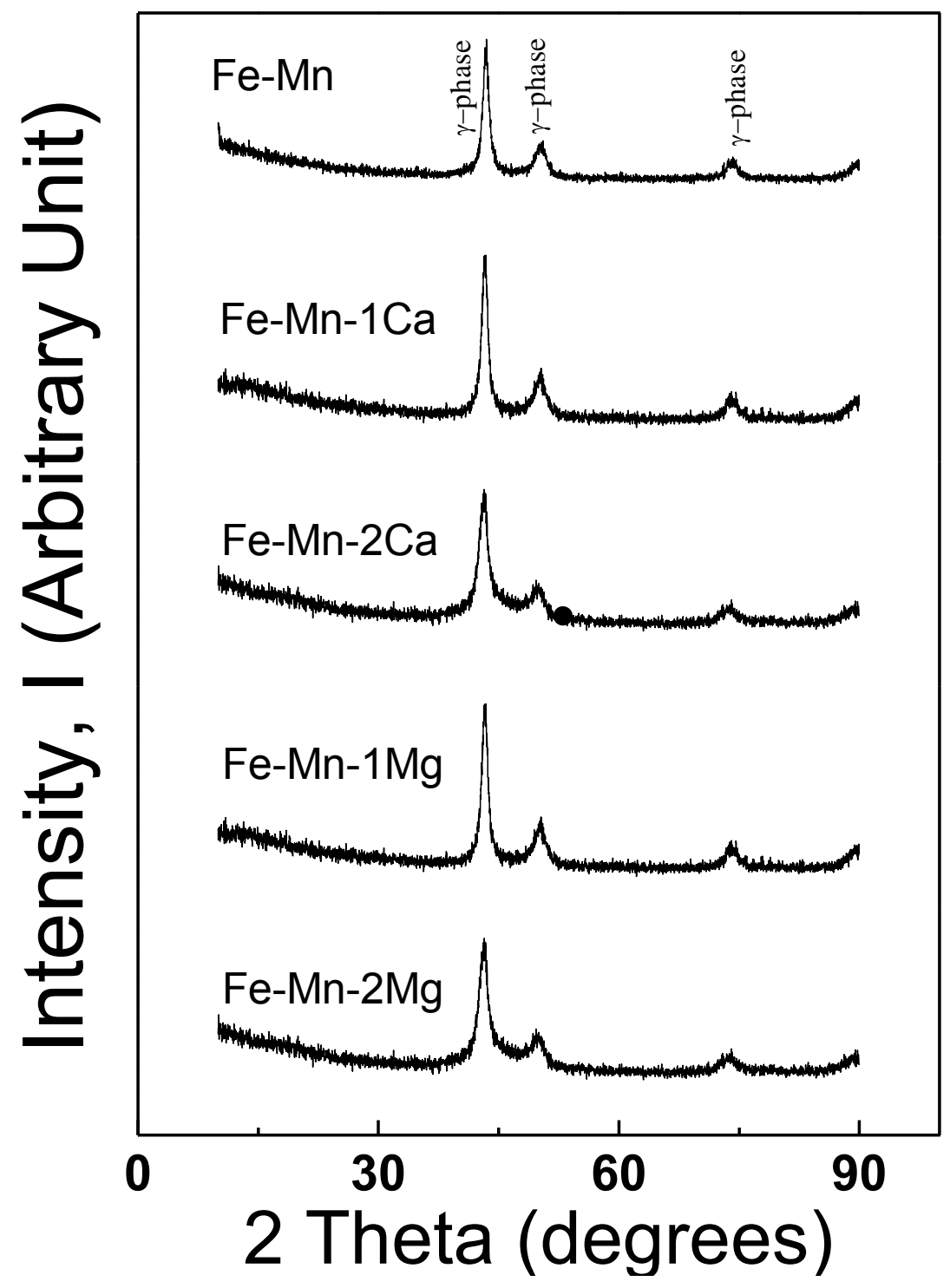

Figure 2. X-ray diffraction patterns of Fe-Mn, Fe-Mn-Ca, and Fe-Mn-Mg alloy powders. 


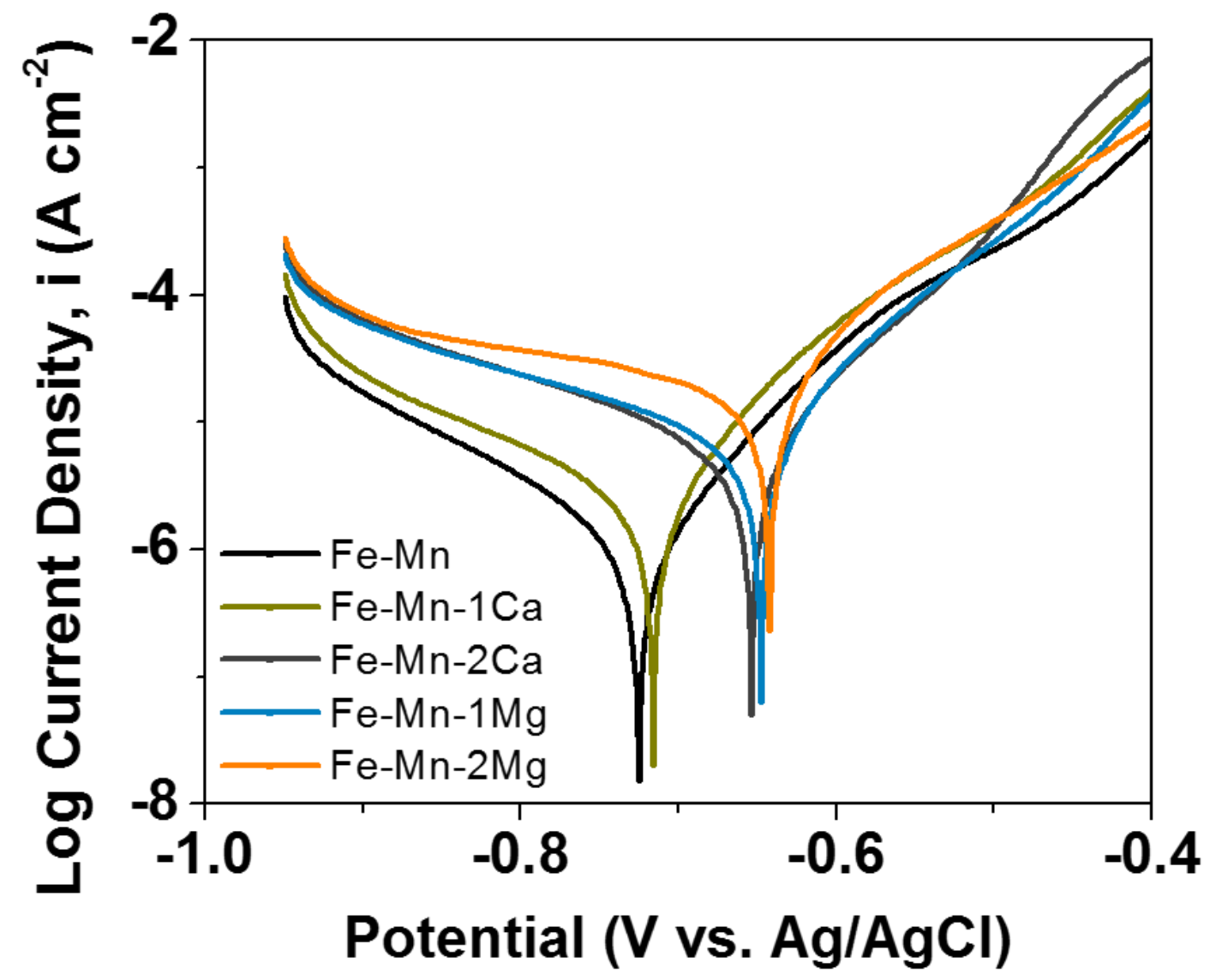

Figure 3. Tafel curves from potentiodynamic polarization measurements of Fe-Mn, Fe-Mn-Ca, and Fe$\mathrm{Mn}-\mathrm{Mg}$ compacted pellets.

Material

Corrosion potential, $\mathrm{E}_{\text {corr }}$

$-0.72 \pm 0.04$

$-0.71 \pm 0.02$

$-0.66 \pm 0.02$

$-0.65 \pm 0.02$

$-0.64 \pm 0.03$
Corrosion current density, $i_{\text {corr }}$

$$
\left[\mu \mathrm{A} \mathrm{cm}^{-2}\right]
$$

$1.00 \pm 0.06$

$2.12 \pm 0.92$

$6.36 \pm 1.75$

Fe-Mn-1Mg

Fe-Mn-2Mg

$9.16 \pm 1.25$

Table 1. Corrosion potential and corrosion current density of Fe-Mn, Fe-Mn-Ca, and Fe-Mn-Mg compacted pellets $(n=3)$. 

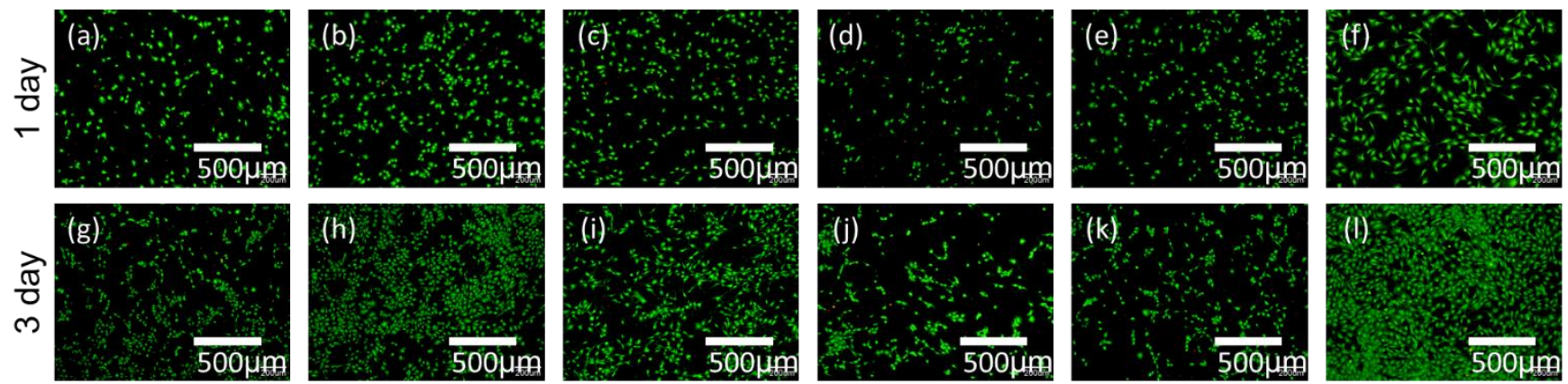

Fe-Mn-1Mg Fe-Mn-2Mg

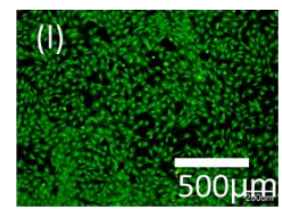

Control

Figure 4. Fluorescent images of live dead cell viability of MC3T3-E1 cells seeded on the compacted pellets of (a) Fe-Mn, (b) Fe-Mn-1Ca, (c) Fe-Mn-2Ca, (d) Fe-Mn-1Mg, (e) Fe-Mn-2Mg, and (f) cell culture plastic control after 1 day culture images (a)-(f). Respective results of the 3 day culture are seen in fluorescence images (g)-(l). 

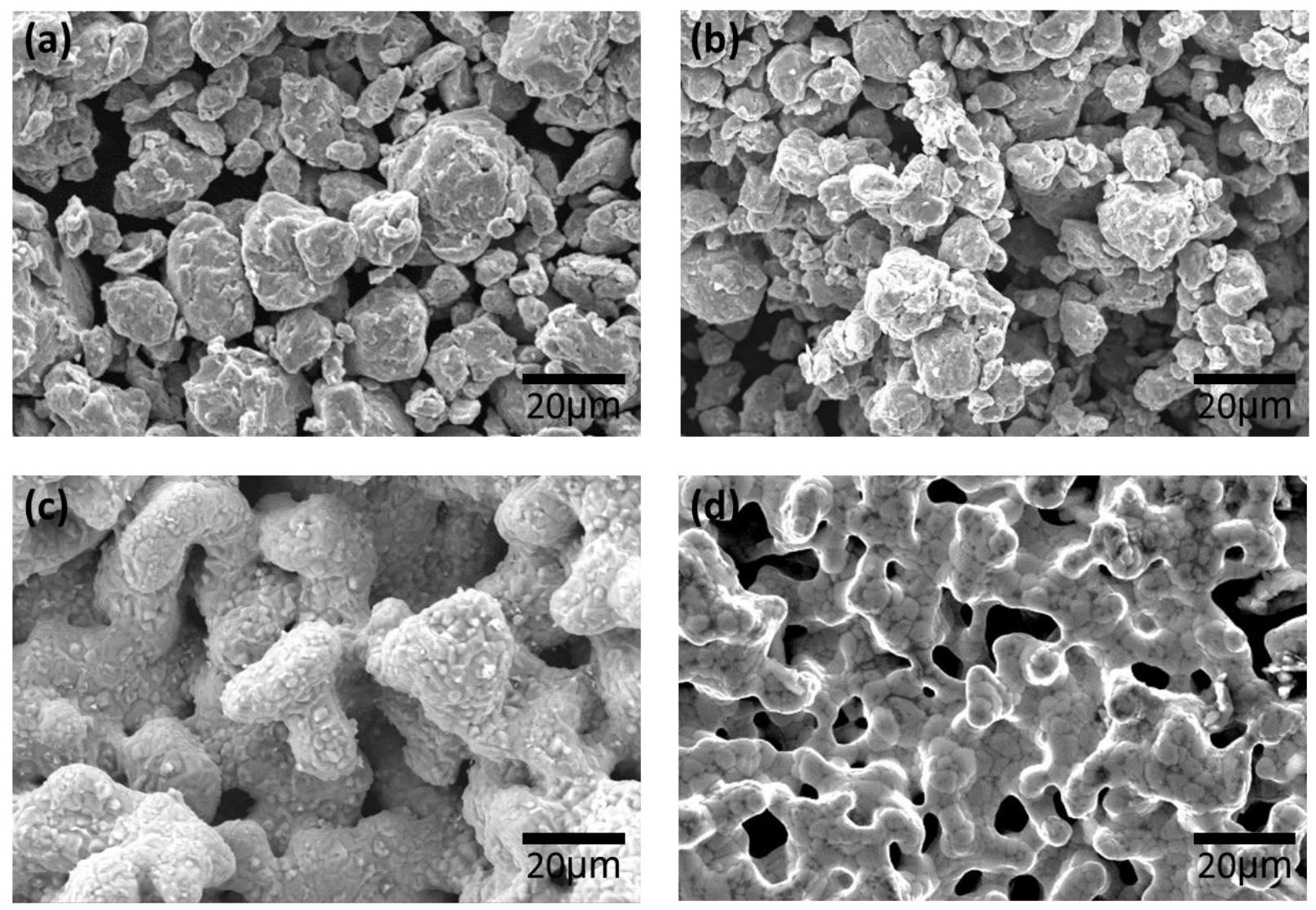

Figure 5. Morphology of (a) Fe-Mn powders (b) Fe-Mn-1Ca powders, (c) 3DP Fe-Mn sample, and (d) 3DP Fe-Mn-1Ca sample.

\begin{tabular}{ccccc}
\hline & $\begin{array}{c}\text { Absolute density } \\
{\left[\mathrm{g} / \mathrm{cm}^{3}\right]}\end{array}$ & $\begin{array}{c}\text { Envelope density } \\
{\left[\mathrm{g} / \mathrm{cm}^{3}\right]}\end{array}$ & $\begin{array}{c}\text { Open porosity } \\
{[\%]}\end{array}$ & $\begin{array}{c}\text { Percent of shrinkage } \\
{[\%]}\end{array}$ \\
3DP Fe-Mn & $7.73 \pm 0.01$ & $4.69 \pm 0.12$ & $39.3 \pm 1.5$ & $31.6 \pm 1.6$ \\
3DP Fe-Mn-1Ca & $7.48 \pm 0.04$ & $3.53 \pm 0.10$ & $52.9 \pm 1.1$ & $11.7 \pm 2.4$ \\
\hline
\end{tabular}

Table 2. Density, porosity, and shrinkage measurements after sintering of 3DP Fe-Mn and Fe-Mn-1Ca. 


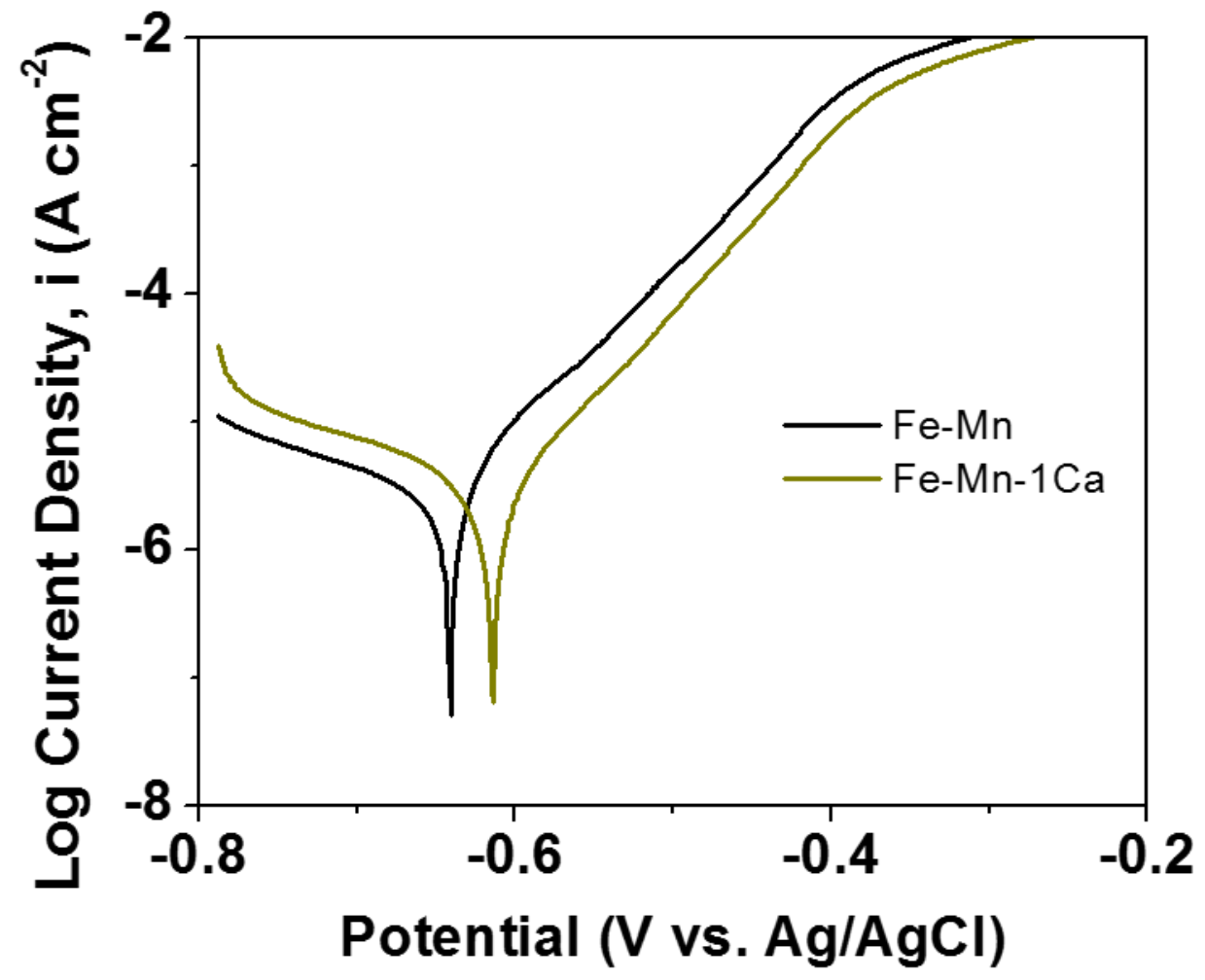

Figure 6. Representative tafel curves from potentiodynamic polarization measurement of 3DP Fe-Mn, and Fe-Mn-1Ca $(n=4)$.

\begin{tabular}{cccc}
\hline & $\begin{array}{c}\text { Corrosion potential, } \\
\text { E corr [V] }\end{array}$ & $\begin{array}{c}\text { Corrosion current density, } \\
\text { I corr }\left[\mu \mathrm{A} / \mathrm{cm}^{2}\right]\end{array}$ & $\begin{array}{c}\text { Corrosion rate, } \\
\text { CR [ mm/year] }\end{array}$ \\
Fe-Mn & $-0.64 \pm 0.02$ & $2.21 \pm 0.35$ & $0.04 \pm 0.01$ \\
Fe-Mn-1Ca & $-0.63 \pm 0.02$ & $2.88 \pm 0.54$ & $0.07 \pm 0.01$ \\
\hline
\end{tabular}

Table 3. Corrosion potential and corrosion current density of 3DP Fe-Mn and Fe-Mn-1Ca. 

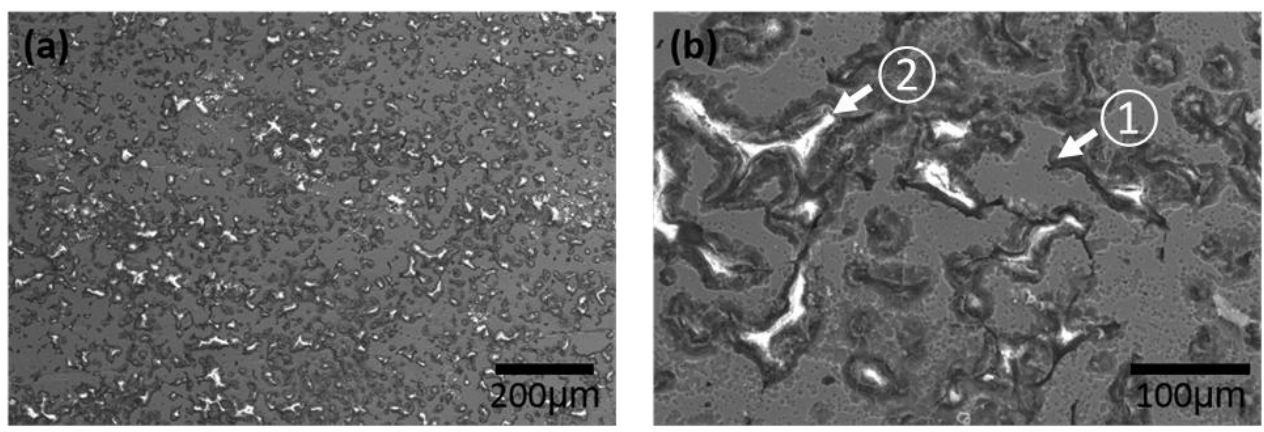

\begin{tabular}{c|cc}
\hline & (1) & (2) \\
\hline $\mathrm{Fe}$ & 62.3 & 21.3 \\
$\mathrm{Mn}$ & 33.8 & 5.0 \\
$\mathrm{O}$ & 3.9 & 73.7 \\
& & \\
\hline
\end{tabular}
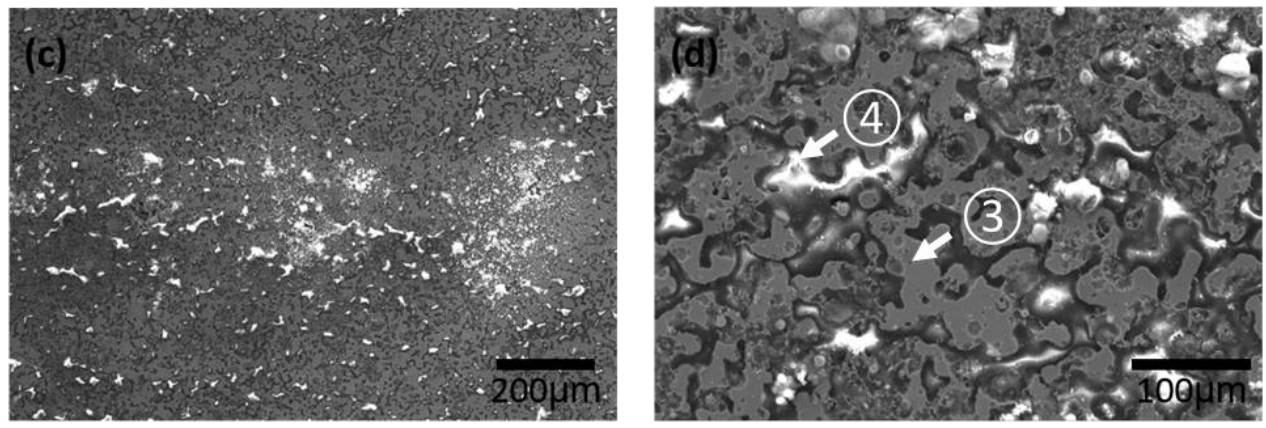

\begin{tabular}{c|cc}
\hline & (3) & (4) \\
\hline $\mathrm{Fe}$ & 63.1 & 28.4 \\
$\mathrm{Mn}$ & 33.1 & 10.0 \\
$\mathrm{Ca}$ & 0.6 & 9.7 \\
$\mathrm{O}$ & 3.2 & 51.9 \\
\hline
\end{tabular}

Figure 7. Surface morphology and elemental analysis (EDX) of 3DP Fe-Mn at (a) 100x (b) 500x and 3DP $\mathrm{Fe}-\mathrm{Mn}-1 \mathrm{Ca}$ at (c) 100x (d) 500x after potentiodynamic polarization measurement.

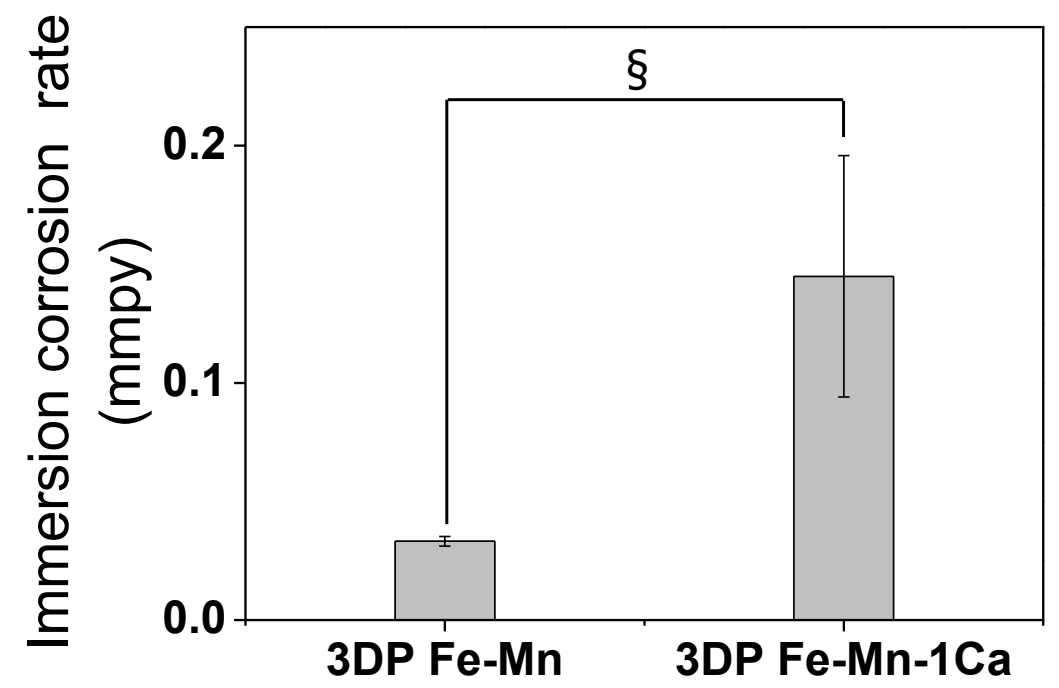

Figure 8. Immersion corrosion rates of 3DP Fe-Mn and Fe-Mn-1Ca after the immersion in HBSS for 28 days $(n=3, \S p<0.05$ denotes a significant difference with all other groups). 

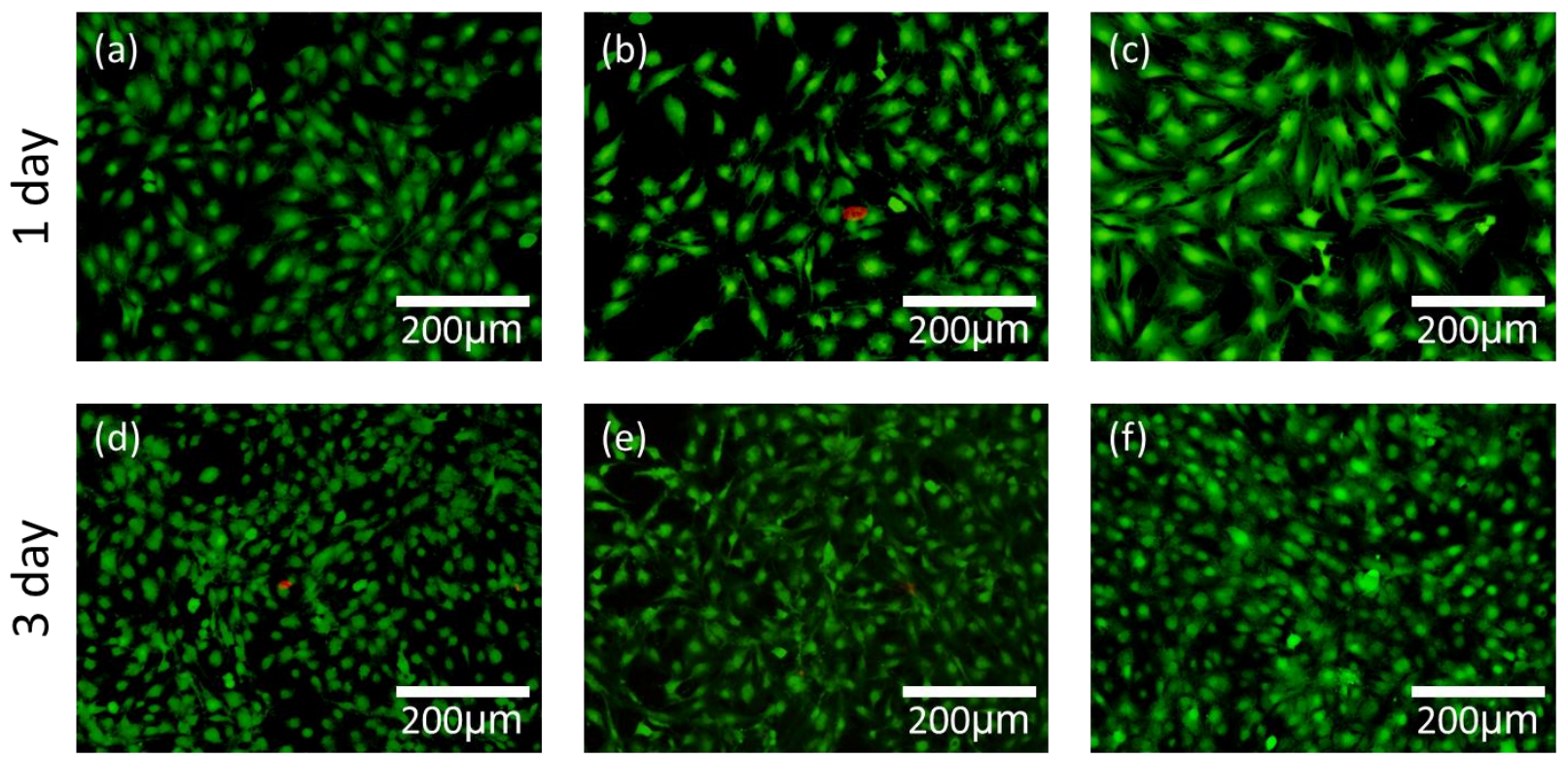

Figure 9. Fluorescence images of live dead cell viability of MC3T3-E1 cells on (a,d) 3DP Fe-Mn, (b,e) 3DP Fe-Mn-1Ca, and (c) cell culture plastic control after 1 day culture images (a)-(c). Respective results after 3 days culture are seen in the fluorescence images (d)-(f). 

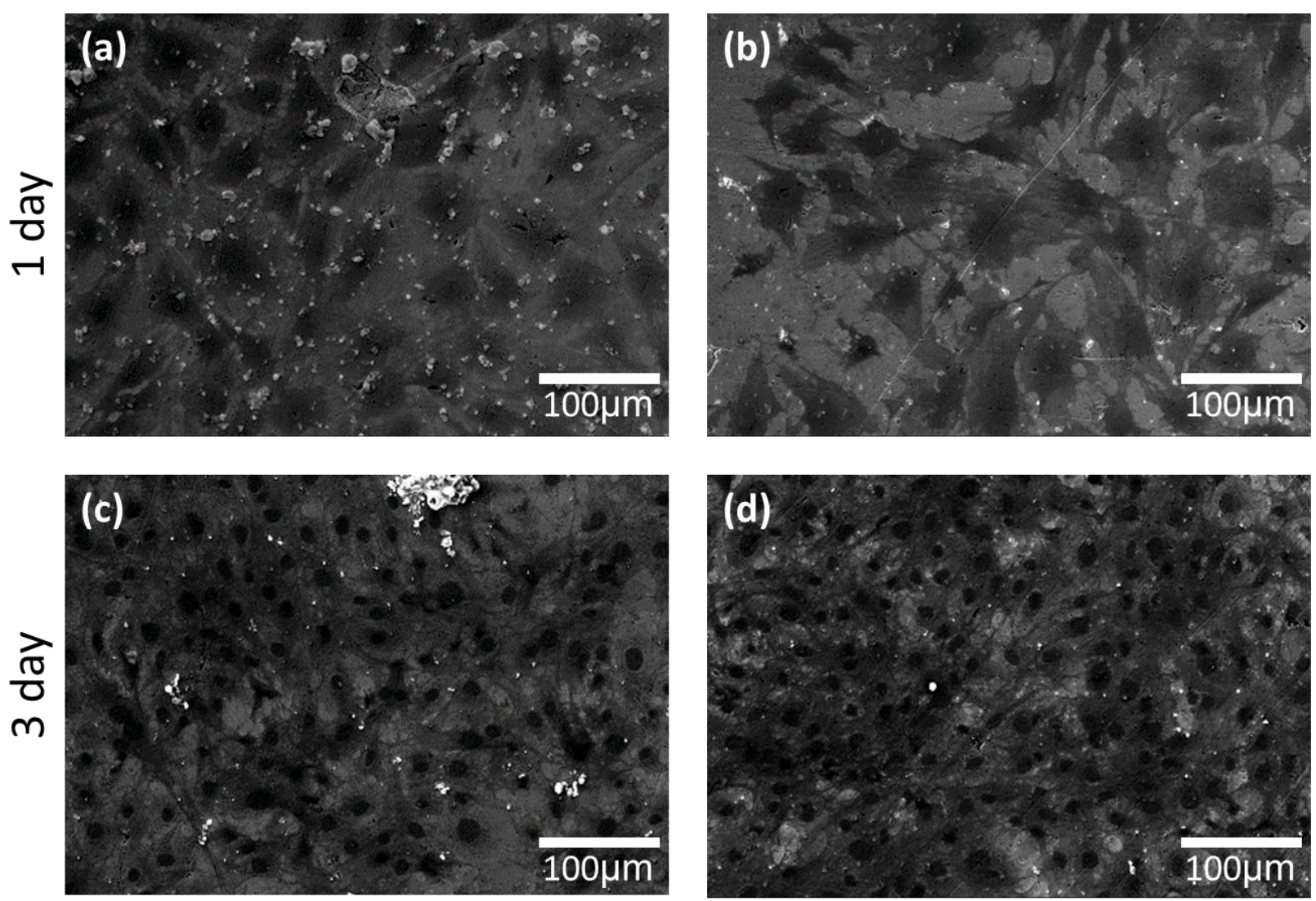

Figure 10. Scanning electron microscopy (SEM) images of fixed MC3T3-E1 cells after live dead cell viability assay on (a) 3DP Fe-Mn and (b) 3DP Fe-Mn-1Ca for 1 day culture. Respective SEM images of fixed cells for 3 day culture are shown in images (c)-(d). 


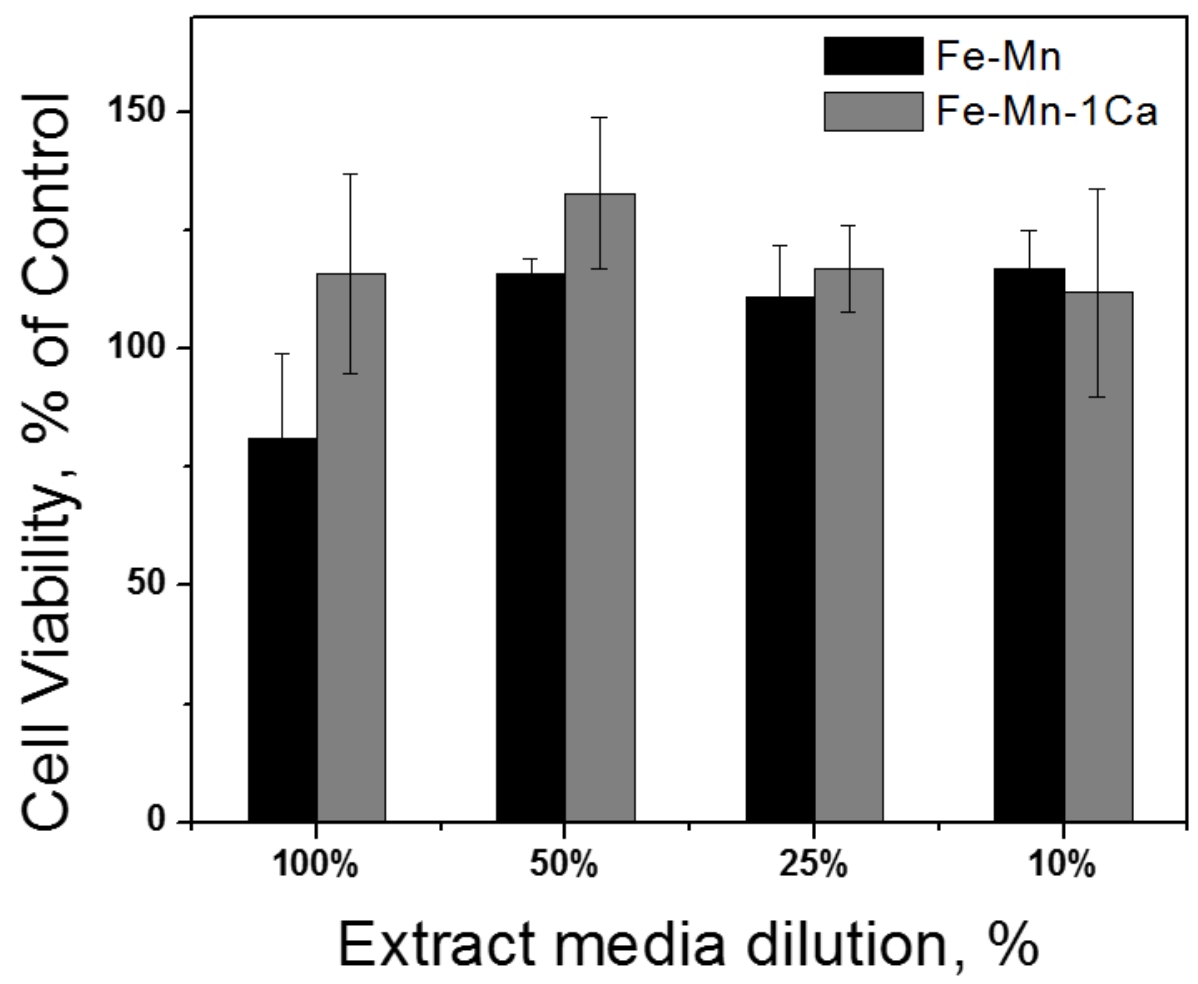

Figure 11. Indirect MTT cell viability of MC3T3-E1 cells cultured for 3 days with the extract media of 3DP Fe-Mn and Fe-Mn-1Ca (n=3).

\begin{tabular}{cccc}
\hline & Fe (ppm) & Mn (ppm) & Ca (ppm) \\
Fe-Mn & $3.0 \pm 0.1$ & $4.5 \pm 0.4$ & - \\
Fe-Mn-1Ca & $4.4 \pm 1.5$ & $4.4 \pm 1.6$ & $29.1 \pm 11.6$ \\
\hline
\end{tabular}

Table 4. Fe, Mn, and Ca concentration in the extract media of 3DP Fe-Mn and Fe-Mn-1Ca. 


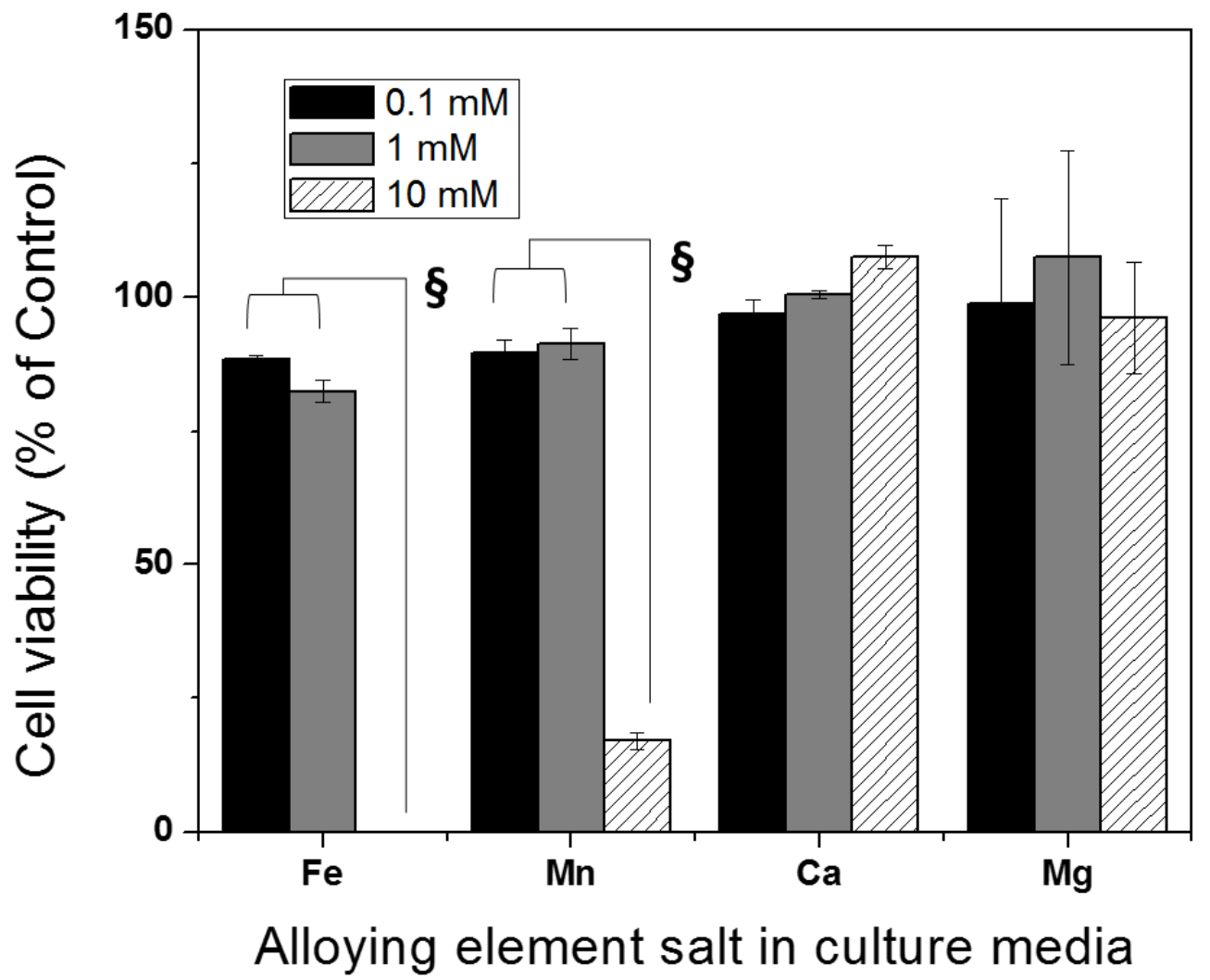

Figure 12. MC3T3-E1 cytocompatibility of $\mathrm{Fe}, \mathrm{Mn}, \mathrm{Ca}$, and $\mathrm{Mg}$ salt in culture medium at 0.1 , 1 , and 10 $\mathrm{mM}$ concentrations after 7 days of culture $(n=3, \S p<0.05$ denotes a significant difference with all other groups). 


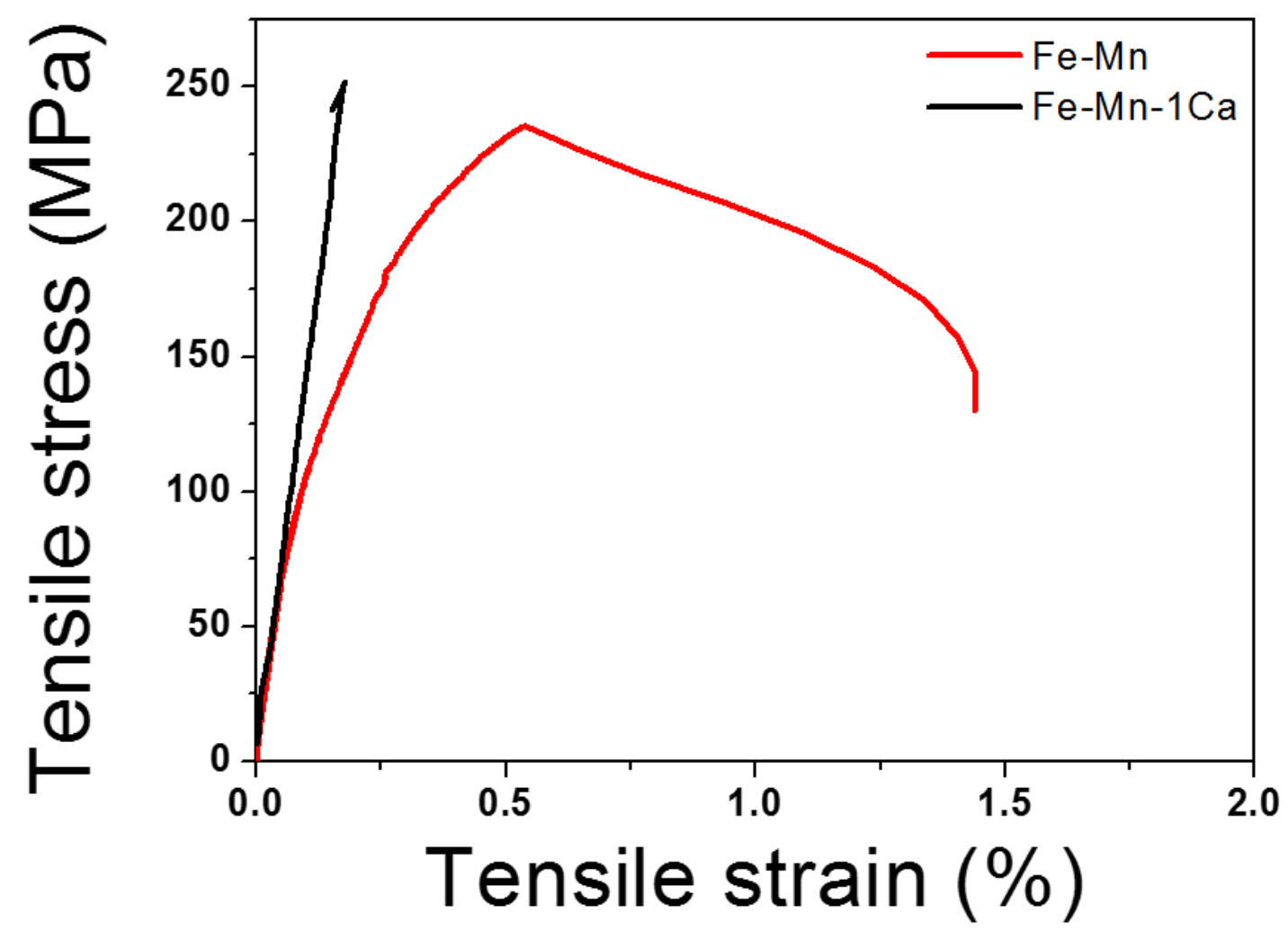

Figure 13. Representative stress vs. strain curves from tensile testing of 3DP Fe-Mn and Fe-Mn-1Ca.

\begin{tabular}{cccc}
\hline Materials & $\begin{array}{c}\text { Ultimate Tensile } \\
\text { Strength }(\mathrm{MPa})\end{array}$ & Modulus (GPa) & $\begin{array}{c}\text { Yield Tensile Strength } \\
(\mathrm{MPa})\end{array}$ \\
Fe-Mn & $228.1 \pm 10.6 \S$ & $39.1 \pm 0.5 \S$ & $189.7 \pm 25.6$ \\
Fe-Mn-1Ca & $296.6 \pm 45.8 \S$ & $163.4 \pm 21.0 \S$ & - \\
\hline
\end{tabular}

Table 5. Tensile properties of 3DP Fe-Mn and Fe-Mn-1Ca $(n=5, \S p<0.05$ denotes a significant difference between two groups). 
$-\mathbf{m}-\mathrm{Fe}_{0.65} \mathrm{Mn}_{0.35-\mathrm{x}} \mathrm{Ca}_{\mathrm{x}}$

$-\bullet-\mathrm{Fe}_{0.65} \mathrm{Mn}_{0.35-\mathrm{x}} \mathrm{Mg}_{\mathrm{x}}$

Figure 1. Results of CALPHAD simulations on the effect of adding $\mathrm{Ca}$ and $\mathrm{Mg}$ to binary Fe-Mn alloy for enhanced corrosion.

Fe-Mn

Fe-Mn-1Ca

$\mathrm{Fe}-\mathrm{Mn}-2 \mathrm{Ca}$

Fe-Mn- $1 \mathrm{Mg}$

Fe-Mn-2Mg

Figure 2. X-ray diffraction patterns of Fe-Mn, Fe-Mn-Ca, and Fe-Mn-Mg alloy powders.

-Fe-Mn

$-\mathrm{Fe}-\mathrm{Mn}-1 \mathrm{Ca}$

$-\mathrm{Fe}-\mathrm{Mn}-2 \mathrm{Ca}$

$-\mathrm{Fe}-\mathrm{Mn}-1 \mathrm{Mg}$

$-\mathrm{Fe}-\mathrm{Mn}-2 \mathrm{Mg}$

Figure 3. Tafel curves from potentiodynamic polarization measurements of $\mathrm{Fe}-\mathrm{Mn}, \mathrm{Fe}-\mathrm{Mn}-\mathrm{Ca}$, and $\mathrm{Fe}-$ Mn-Mg compacted pellets.

-Fe-Mn

$-\mathrm{Fe}-\mathrm{Mn}-1 \mathrm{Ca}$

Figure 6. Representative tafel curves from potentiodynamic polarization measurement of 3DP Fe-Mn, and Fe-Mn-1Ca $(n=4)$. 
-Fe-Mn

-Fe-Mn-1Ca

Figure 11. Indirect MTT cell viability of MC3T3-E1 cells cultured for 3 days with the extract media of 3DP Fe-Mn and Fe-Mn-1Ca (n=3).

\section{$0.1 \mathrm{mM}$ \\ $1 \mathrm{mM}$ \\ V/I $10 \mathrm{mM}$}

Figure 12. MC3T3-E1 cytocompatibility of $\mathrm{Fe}, \mathrm{Mn}, \mathrm{Ca}$, and $\mathrm{Mg}$ salt in culture medium at $0.1,1$, and 10 $\mathrm{mM}$ concentrations after 7 days of culture $(n=3, \S p<0.05$ denotes a significant difference with all other groups).

$-\mathrm{Fe}-\mathrm{Mn}$

-Fe-Mn-1Ca

Figure 13. Representative stress vs. strain curves from tensile testing of 3DP Fe-Mn and Fe-Mn-1Ca. 

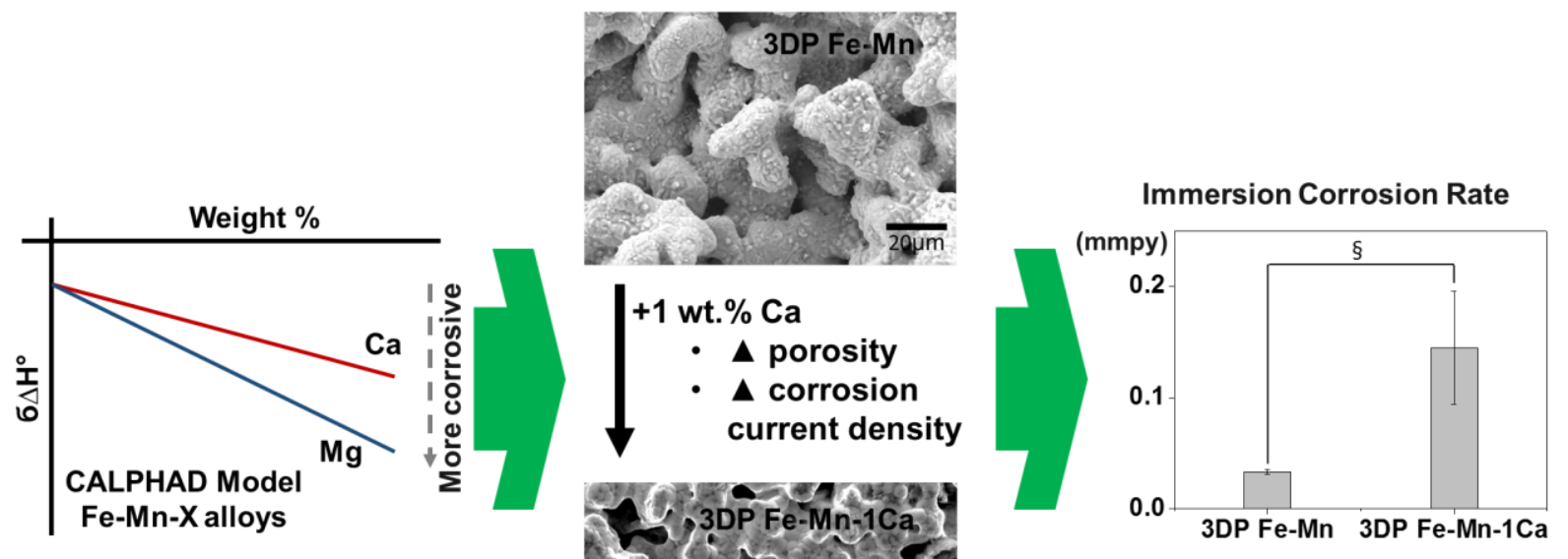